\title{
ESPACIO HABITACIONAL/ESPACIO GRÁFICO: GRABADOS AL AIRE LIBRE EN EL TÉRMINO DE LA HINOJOSA (CUENCA)
}

\author{
RESIDENCE SPACE/GRAPHIC SPACE: \\ ENGRAVINGS IN THE OPEN AIR \\ IN THE MUNICIPALITY OF LA HINOJOSA \\ (CUENCA)
}

\author{
PRIMITIVA BUENO RAMÍREZ (*) \\ RODRIGO DE BALBÍN BEHRMANN (*) \\ MARGARITA DÍAZ-ANDREU (**) \\ AMPARO ALDECOA QUINTANA (*)
}

\section{RESUMEN}

El trabajo que ahora presentamos se basa en el análisis de las grafías, su ubicación en el soporte y su relación con el entorno, en una zona concreta, el término de La Hinojosa, en Cuenca, lugar en el que tenemos bien documentadas ocupaciones calcolíticas y de la Edad del Bronce. Nuestra propuesta es la de comprender dichos grabados como una parte de las expresiones del Arte Esquemático peninsular, en este caso asociadas a un contexto habitacional y, a partir de ahí, aportar elementos para la comprensión de su "mensaje" desde una perspectiva más amplia que incluye otros contextos habitacionales para conjuntos de grabados al aire libre en la Península Ibérica.

\begin{abstract}
The work that now we present is based on the analysis of graphic designs, their location and their relationship to the environment, in the municipality of La Hinojosa Cuenca, a place where we have well documented occupations of the Copper and Bronze Ages. Our aim is to understand these engravings as part of the expressions of

(*) Área de Prehistoria. Universidad de Alcalá de Henares. C/ Colegios, 2. 28801 Alcalá de Henares. Madrid.

(**) Department of Archeology. University of Durham. South Road. Durham DH1 LE. Gran Bretaña.

El artículo fue remitido en su versión final el 20-I-98.
\end{abstract}

peninsular Schematic Art, in this case associated with an occupational context, and to provide elements for the comprehension of its message in a broader context that includes occupational contexts for other open aire engravings in the Iberian Peninsula.

Palabras clave: Arte Esquemático. Grabados al aire libre. Contextos habitacionales. Calcolítico. Bronce.

Key words: Schematic Art. Open air engravings. Occupational contexts. Copper Age. Bronze Age.

\section{INTRODUCCIÓN}

Los estudios dedicados al Arte Esquemático peninsular han tenido como base, desde finales de los 60, el trabajo de P. Acosta, quedando bastante relegados los trabajos realizados por investigadores de la primera parte de este siglo. El libro de Acosta (1968) se centra en los ejemplos pictóricos, dejando de lado la concepción más amplia del Arte Esquemático que proponía H. Breuil (1935), de cuya publicación la autora (Acosta, 1968) toma una gran parte de los datos. Sólo en fechas muy recientes algunos investigadores han insistido en la complejidad del conjunto gráfico que denominamos Arte Esquemático, la cual incluye figuraciones al aire libre con técnicas de grabado 
(Gómez Barrera, 1992) o grabados y pinturas al interior de monumentos sepulcrales (Bueno Ramírez y Balbín Behrmann, 1992).

Creemos que hoy día puede afirmarse la coexistencia de diversas versiones gráficas sobre distintos soportes, y desde luego, una variedad de mensajes que sólo análisis pormenorizados de las grafías, su situación, asociación en el soporte y relación con el entorno ambiental, nos permitirán ir delimitando.

Otro de los asertos que caracterizaba el análisis del Arte Esquemático era el de su situación geográfica preponderante en la zona sur de la Península (Acosta, 1968: 17).

Con ambas premisas, la técnica y la situación geográfica, los grabados quedaban sensiblemente relegados, pues técnicamente no encajaban en la propuesta y su situación geográfica era mucho mayor que la exclusivamente sureña. Esto explica el desconocimiento que de ellos hemos tenido hasta fechas muy recientes, salvedad hecha de los petroglifos gallegos con una tradición de estudio que posee más de un siglo, claramente respaldada en la investigación peninsular.

\section{APROXIMACIÓN A LOS DATOS. METODOLOGÍA}

Una primera aproximación a los datos es la que parte del trabajo de campo y, por tanto, de la obtención de documentación gráfica. Otra es evidentemente la interpretativa, la explicación de nuestra posición acerca de la comprensión cultural de la cuestión y los argumentos técnicos y formales que avalan nuestra hipótesis.

En la primera parte, la toma de datos sobre el terreno, nos basamos en la metodología más extendida para el análisis del Arte Paleolítico. Desgraciadamente no existe un consenso en los sistemas utilizados para la toma de datos en el Arte Postpaleolítico. Una premisa fundamental, como es la del respeto máximo al soporte, se cumple muy escasamente y se aplican tinturas, como el famoso método bicromático (1), que en nada favorecen la conservación del soporte. Por otra parte,

(1) Consiste en la aplicación sucesiva de dos tinturas diferentes una negra, a la que se superpone otra blanca, con el objetivo de dar realce a los grabados presentes en el soporte. Este sistema ha sido muy utilizado en Portugal, especialmente sobre menhires decorados (Gomes, 1994). si lo que se pretende es la obtención de un calco lo más completo posible, el método bicromático y las demás posibles tinturas cubren y eliminan la pintura, ocultan los grabados finos y, por tanto, ni siquiera contribuyen al fin previsto.

Probablemente ningún investigador usaría estos métodos en cuevas paleolíticas, por difícil que fuese la observación de los grabados, pues existe en el estudio del Arte Paleolítico un consenso básico sobre el respeto al soporte que aún no hemos conseguido entre los investigadores del Arte Postpaleolítico.

La utilización de la fotografía con su enorme cantidad de recursos, constituye para nosotros el punto de partida para la elaboración de los calcos. En el campo realizamos plantas y alzados de los paneles a escala, con la situación y medidas de los motivos visibles. En el laboratorio se elaboran las fotografías, endureciendo los negativos para delimitar al máximo las líneas grabadas, y se procesan las tomas mejores con un programa Adobe Photoshop. Esta información se contrasta con la recogida en las fichas de campo y con ella se elaboran los primeros calcos. Éstos se comprueban de nuevo sobre el terreno y se reinicia el proceso (2). A tenor de la dificultad del yacimiento se hacen más o menos verificaciones de los calcos. El proceso permite, además, acumular gran cantidad de información gráfica, lo que supone un medio más de conservación del Patrimonio rupestre (3).

Nuestra aproximación teórica parte de la admisión de la técnica del grabado como una técnica antigua. Afirmación que se basa en la constatación de la presencia de éste en ambientes antiguos, en su posibilidad de datación y en la relación gráfica de los temas grabados con los pintados (Bueno Ramírez y Balbín Behrmann, 1992; Balbín Behrmann y Bueno Ramírez, 1996a).

Aproximaciones al tema desde la Arqueología del Paisaje demuestran la relación topográfica entre paneles grabados al aire libre y yacimientos antiguos (Bradley et alii, 1994a y b; Bradley y Fábregas, 1996; Peña y Rey, 1993; Villoch, 1995). Este aspecto se ha desarrollado bastante en

(2) Los calcos han sido elaborados por A. Aldecoa, R. de Balbín y P. Bueno, y pasados a limpio por A. Aldecoa, J.J. Alcolea, S. Ruiz y B. de Andrés. Las fotografás y su posterior procesado son obra de R. Balbín.

(3) Sobre digitalización y archivo de imágenes para su conservación: Vicent García, 1994; Vicent García et alii, 1996; Vicent et alii, 1997. 
el ámbito de estudio de los Petroglifos gallegos, aunque no así en otras zonas de la Península. Nuestro estudio de dispersión de yacimientos (4) en el término de La Hinojosa y su relación con los soportes grabados, forma parte de esta línea de análisis.

Otros componentes necesarios en las manifestaciones gráficas son el estilo y técnica de los grabados y el análisis asociativo de las distintas grafías. La metodología más desarrollada, que es la aplicada al Arte Paleolítico, aboga por clasificar éste a partir del conocimiento y existencia de unos "estilos" reflejo de tipos formales y ubicaciones en el espacio. Los estilos poseen connotaciones cronológicas que se establecen a partir de comparaciones con objetos muebles localizados en estratigrafía.

Nosotros hemos sostenido que para el Arte Esquemático pueden tomarse referencias arqueológicas, a partir del estudio del Arte Megalítico (Bueno Ramírez y Balbín Behrmann, 1992, 1997), con sus diversos componentes pintados y grabados sobre los megalitos, en esculturas exentas (Bueno Ramírez, 1991, 1995), en diversas versiones muebles (Bueno Ramírez, 1992), o al aire libre, caso admitido para los menhires. El análisis del Arte Megalítico, su conocimiento exhaustivo y su posibilidad de datación pueden constituirse en un punto de partida para elaborar una tipología estilística de las manifestaciones gráficas postpaleolíticas, que en unos años nos permita concretar atribuciones culturales y cronológicas. Por tanto, en la interpretación que proponemos para los grabados de La Hinojosa, expondremos relaciones estilísticas, en el sentido de formas y asociaciones gráficas, que consideramos significativas.

La variedad de soportes, la variedad de técnicas, y la regionalización de los contenidos, nos obligan a buscar explicaciones para el Arte Esquemático concebido como nosotros proponemos. Recordaremos aquí la multitud de técnicas y soportes del Arte Paleolítico y sus versiones regionales, lo que no impide que se considere como un todo desde el punto de vista de su análisis.

(4) Los datos sobre la situación de los yacimientos Calcolíticos y de la Edad del Bronce en el término de La Hinojosa, se basan en el análisis territorial realizado por M. Díaz-Andreu (1994) para su tesis doctoral. Fue esta investigadora la que nos dio a conocer la existencia de estos grabados, en su día descubiertos y dados a conocer en prensa por D. Vicente Martínez Millán.

\section{ARTE ESQUEMÁTICO EN LA PROVINCIA DE CUENCA}

Establecido que nuestro análisis parte de la base de la calificación de los grabados al aire libre de La Hinojosa comoArte Esquemático, conviene realizar un pequeño resumen de lo conocido de estas manifestaciones en la provincia de Cuenca (Fig. 1).

Por lo que se refiere a la pintura, el primer conjunto dado a conocer fue el de Villar del Humo (Hernández Pacheco, 1921, 1959; Almagro, 1946). Siguiendo las pautas de la época, y al no encontrarse en la zona clásica, el conjunto de Villar del Humo se interpretó como marginal y de ahí los raros sincretismos entre Arte Levantino y Arte Esquemático que se proponían para el mis-

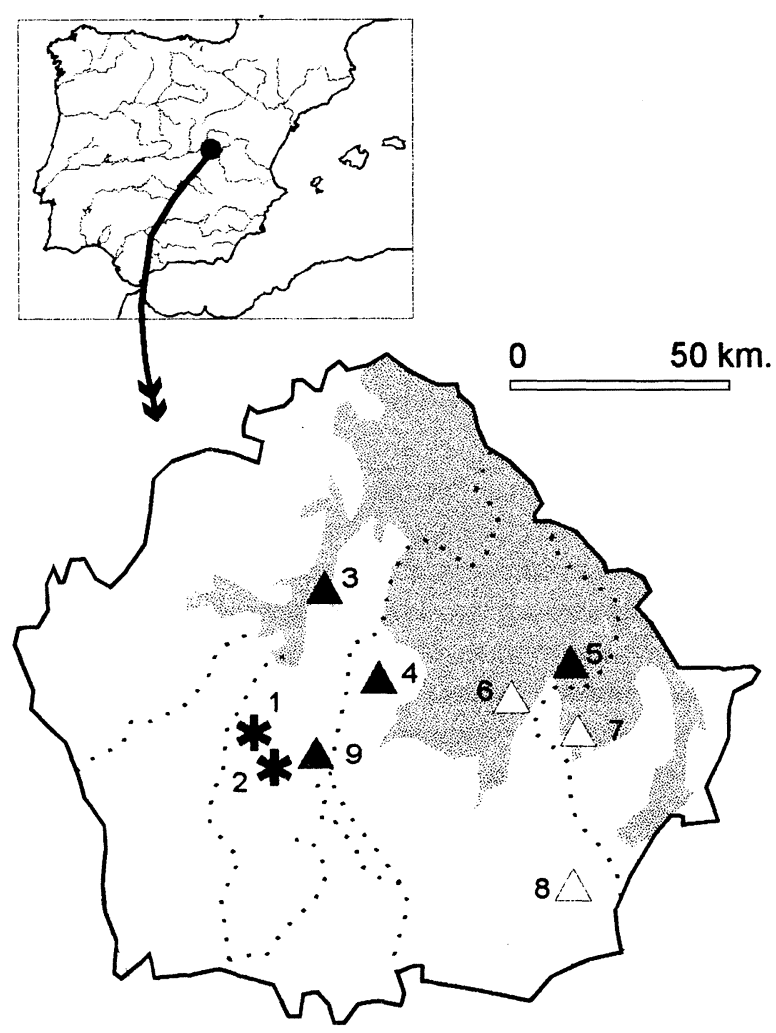

Fig. 1. Situación de la provincia de Cuenca en la Península Ibérica con inclusión de las localidades con Arte Esquemático: grabados al aire libre ( $\mathbf{\square})$ : 1 La Hinojosa, 2. Cervera del Llano; representaciones antropomorfas $(\mathbf{A})$ : 3. Chillarón de Cuenca, 4. La Parra de las Vegas, 5. Boniches, 1. La Cruz de San Bernardino; pintura en abrigos $(\triangle):$, Carboneras de Guadazaón, 8. Villar del Humo, 9. Minglanilla. 
mo. Este importante conjunto ha tenido algunos estudios posteriores (Acosta, 1983; Alonso, 1984, 1985; Alonso et alii, 1982) que indican la complejidad de lo representado y el interés de su estudio, que me-rece una monografía como la que creemos está en preparación por parte del equipo de Anna Alonso.

En los años 80 comenzaron a aparecer más evidencias de Arte Esquemático pintado en Cuenca, concretamente en el río Guadazaón, descubiertas por el grupo espeleológico Lobetum (5). Sólo uno de los abrigos estudiados en aquel momento fue publicado, el de la Peña de Aldebarán (Piñón, 1987).

Los descubrimientos continúan y en 1992 se publica el abrigo de la Hoz de Vicente (Martínez Perelló y Díaz-Andreu, 1992). Este abrigo contiene elementos levantinos y de Arte Esquemático al igual que otros muchos de la zona de Levante o de La Mancha.

La presencia de grabado al aire libre es un hecho conocido en la provincia de Cuenca, pero habitualmente no publicado. En un trabajo reciente (Balbín Behrmann y Bueno Ramírez, 1994) recogíamos esta situación, en la que Cuenca quedaba como un hueco, mientras teníamos importantes conjuntos enAlbacete (Balbín Behrmann y Bueno Ramírez, 1981; Jordán Montes y Sánchez Gómez, 1988; Maya, 1977), Murcia (Molina, 1985), y, sobre todo, en el País Valenciano (Hernández et alii, 1986, 1988) y Teruel (Gómez Barrera, 1992: 326329 ).

Los grabados en cueva tienen en Cuenca un solo ejemplo publicado, el de la Sima del Cérro "Cabeza de la Fuente" (Martínez Navarrete y Pérez Sierra, 1985). En su monografía se incluye un apéndice para el análisis de estos grabados (Bécares et alii, 1985: 123-143). Los autores describen una figura humana con ojos, cejas, nariz, boca triangular y el cuerpo sugerido por el volumen del soporte, situando su realización en la Edad del Hierro.

La presencia de una figura antropomorfa postpaleolítica, esta vez en cueva, ratificaba la existencia de Arte Esquemático en Cuenca y su relación con las figuraciones antropomorfas tan propias del

(5) El grupo está compuesto por Víctor de la Vega Almagro, Santiago Prieto Villar y Julián García Turrado. Gracias a ellos, uno de nosotros (P.B.), pudo estudiar junto con F. Piñón varios abrigos pintados de los allí presentes. Desgraciadamente, problemas personales que no hacen al caso, impidieron la publicación total del trabajo.
Neolítico, Calcolítico y Bronce en la Península Ibérica. En esas fechas ya se había publicado el ídolo de Chillarón (Almagro Basch, 1966) y el de Parra de las Vegas (Bueno Ramírez, 1983), ejemplos de la existencia de ese arte antropomorfo en nuestra provincia.

La documentación de importantes conjuntos al aire libre, como el que aquí presentamos, y como los que sabemos existen en el término de Cervera del Llano, nos permite augurar un panorama diferente en los próximos años para el estudio delArte Esquemático en esta zona del interior peninsular.

\section{LOS DATOS: GRABADOS AL AIRE LIBRE EN EL TÉRMINO DE LA HINOJOSA (CUENCA)}

El término de La Hinojosa se sitúa en plena zona manchega conquense, al sur de la provincia, en un lugar de transición entre los valles del Júcar y del Guadiana. En la actualidad, el Júcar está embalsado y nuestro sector se encuentra surcado por pequeños arroyos y ramblas, entre las que habría que destacar, por su importancia en la distribución del paisaje, la rambla de la Alcudia. Es igualmente destacable la existencia de fuentes en abundancia que explican la riqueza agrícola del valle, situado entre los afloramientos rocosos de $\mathrm{La}$ Hinojosa y Cervera al Este, y los del Pilar y Sierra Negra al Oeste (Lám. I).

Los mencionados afloramientos se ubican en torno a los $900 \mathrm{~m}$. sobre el nivel del mar. Su composición geológica es de calizas alternando con areniscas (Bullón y Díaz-Andreu, 1992). La ma-

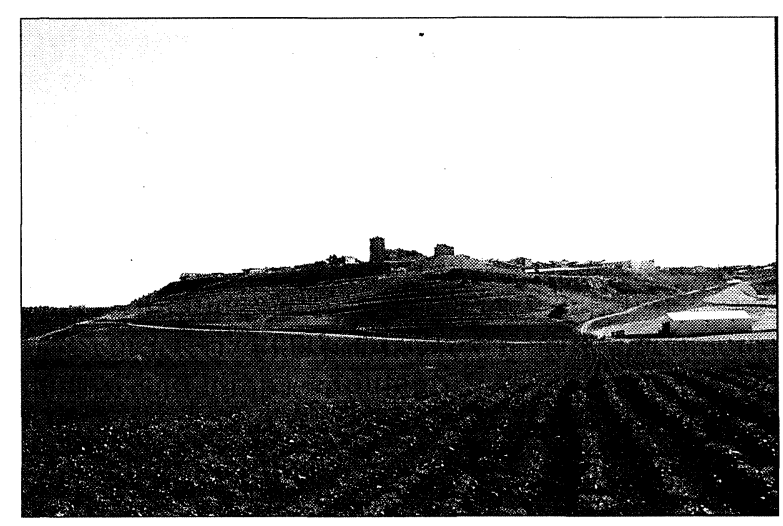

Lám. I. El pueblo actual de La Hinojosa situado sobre los farallones rocosos que dominan el valle (Foto R. de Balbín). 
yor parte de los poblados calcolíticos documentados se asientan sobre estos afloramientos rocosos, con claro control sobre el valle próximo. Su situación convierte a éste, además, en un paso natural entre la región valenciana y la Meseta.

Los grabados del término de La Hinojosa se distribuyen en 11 localizaciones (6), cuyos nombre y situación en coordenadas U.T.M. sobre la Hoja 662 del mapa 1:50.000, reflejamos en el cuadro adjunto (Tab. 1). En éste constan igualmente la cantidad de paneles grabados y una identificación sucinta de sus grafías y asociaciones. No aparecen medidas, pues las escalas dan suficiente referencia gráfica (7).

\section{TÉCNICAS, TEMAS Y ASOCIACIONES}

La técnica más extendida en estos conjuntos al aire libre es la del piqueteado. Consiste en golpear la piedra con otro instrumento, normalmente de piedra también, con movimientos secuenciados que permiten obtener una línea. Ésta posteriormente se repasa, bien con mayor profusión de golpes, bien mediante abrasión.

A veces se producen auténticas excavaciones, llegando a ser determinados motivos, especialmente las cazoletas, muy profundos.

La apariencia del piqueteado puede ser más fina o menos, en relación a la anchura del canal obtenido, pero en ningún caso se han documentado en la zona de estudio incisiones lineales, que además se conservan peor en este tipo de piedra.

Tampoco se usan preparados previos del soporte, del mismo modo que no son comunes en el Arte Esquemático pintado. El único ejemplo en el que estos preparados están demostrados es en el conjunto del Arte Megalítico, ya sea en ortostatos dolménicos, ya sea en estatuas-menhir, estelas antropomorfas o menhires de contextos dolménicos.

El espacio proporcionado por el soporte se utiliza como recurso gráfico, en diversas versiones. La primera de ellas es la selección del mismo con orientaciones distintas (Tab. 2). Cazoletas y cana-

(6) Todas ellas nos han sido facilitadas por D. Vicente Martínez Millán, que fue maestro de la localidad. No descartamos la existencia de más localizaciones cuando se realice una prospección exhaustiva que, a la luz de lo que presentamos, consideramos de todo punto necesaria.

(7) Un informe exhaustivo que incluye las medidas y descripción detallada de todos los motivos, se encuentra depositado en la Excma. Diputación de Cuenca, entidad que ha financiado nuestros trabajos en La Hinojosa.

\begin{tabular}{|c|c|c|c|c|c|c|c|}
\hline Yacimiento & Situación & 1 & 2 & 3 & 4 & 5 & 6 \\
\hline $\begin{array}{l}\text { Peñas de } \\
\text { Mollana }\end{array}$ & $\begin{array}{l}\text { Lo.550.9 } \\
\text { La.4396.8 }\end{array}$ & $*$ & & & & & \\
\hline El Santo & $\begin{array}{l}\text { Lo. } 550.3 \\
\text { La.4396.8 }\end{array}$ & & & & & & \\
\hline 1 & & & & * & & & \\
\hline 2 & & & & $*$ & & & \\
\hline 3 & & & $*$ & & & & \\
\hline 4 & & * & & & * & & \\
\hline 5 & & & & & & & \\
\hline El Ranal & $\begin{array}{l}\text { Lo.549.5 } \\
\text { La. } 4399.4\end{array}$ & & & & & & \\
\hline 1 & & & & $*$ & & & \\
\hline 2 & & & & & & $*$ & * \\
\hline 3 & & & & $*$ & & & \\
\hline $\begin{array}{c}\text { Cruz S. } \\
\text { Bernardino }\end{array}$ & $\begin{array}{l}\text { Lo.549.5 } \\
\text { La.4398.8 }\end{array}$ & * & & & & & \\
\hline $\begin{array}{c}\text { Roca } \\
\text { Grande S. } \\
\text { Bernardino }\end{array}$ & $\begin{array}{l}\text { Lo.549.4 } \\
\text { La.4398.8 }\end{array}$ & & & & & & \\
\hline 1 & & & $*$ & & & & \\
\hline 2 & & & & & & & \\
\hline 3 & & & $*$ & & & & \\
\hline$\overline{4}$ & & & $*$ & & & & \\
\hline Solanillas & $\begin{array}{l}\text { Lo.549.1 } \\
\text { La. } 4399.3\end{array}$ & & $*$ & & & & \\
\hline Corral & $\begin{array}{l}\text { Lo.549.1 } \\
\text { La.4398.5 } \\
\end{array}$ & & & $*$ & & & \\
\hline Buitrera & $\begin{array}{l}\text { Lo.550.5 } \\
\text { La.4398.5 }\end{array}$ & & & & & & \\
\hline $\begin{array}{l}\text { Viñas } \\
\text { Viejas }\end{array}$ & $\begin{array}{l}\text { Lo.549.0 } \\
\text { La. } 4400.2\end{array}$ & & & & & & \\
\hline 1 & & & $*$ & & & & \\
\hline 2 & & & & $*$ & & & \\
\hline 3 & & & & $*$ & & & \\
\hline Peña Buitre & $\begin{array}{l}\text { Lo.548.7 } \\
\text { La.4400.2 }\end{array}$ & & & & & & \\
\hline 1 & & * & & & & & \\
\hline 2 & & $*$ & & & & & \\
\hline 3 & & $*$ & & & & & \\
\hline 4 & & & & $*$ & & & \\
\hline Cabañuelas & $\begin{array}{l}\text { Lo.549.0 } \\
\text { La. } 4400.7 \\
\end{array}$ & & & & & & \\
\hline 1 & & $*$ & & & & & \\
\hline 2 & & $*$ & & & & & \\
\hline
\end{tabular}

Tab. 1. Localización de los yacimientos con grabados de término de La Hinojosa e identificación de los motivos, sus asociaciones y número de paneles. 1, Antropomorfos. 2, Antropomorfo/cazoleta/línea. 3, Cazoleta/línea. 4, Círculo/línea. 5, Zoomorfos. 6, Geométricos.

les tienen una orientación predominantemente cenital, mientras que los motivos antropomorfos po- 
seen una orientación predominantemente vertical, bastante más visible. Si a esto sumamos que algunos de ellos poseen un tamaño destacable, la visualización de los mismos desde lugares alejados debía ser un hecho. Así los antropomorfos descritos de Peña Buitre o los del Santo. Entre los temas de cazoletas y canales, las primeras parecen detentar un papel de eje en la composición, ratificado por sus excavaciones a veces muy marcadas y por su tamaño.

\begin{tabular}{|c|c|c|c|c|}
\hline & 1 & 2 & 3 & 4 \\
\hline Peñas de Mollana & 1 & & & \\
\hline El Santo & 1 & - & & - \\
\hline El Ranal & & - & & \\
\hline Cruz de S. Bernardino & & - & & \\
\hline Roca de S. Bernardino & 1 & - & & \\
\hline Las Solanillas & & - & & \\
\hline El Corral & & - & & \\
\hline Viñas Viejas 1 & & - & & \\
\hline Viñas Viejas 2 & & - & & \\
\hline Viñas Viejas 3 & & - & - & \\
\hline Peña Buitre & 1 & - & & \\
\hline Las Cabañuelas & & - & - & \\
\hline
\end{tabular}

Tab. 2. Orientación predominante de los temas grabados al aire libre en La Hinojosa: I-vertical; -horizontal. 1, Antropomorfos. 2, Cazoletas. 3, Círculos. 4, Pilas.

Desde luego, no puede maximalizarse esta dicotomía de orientaciones, pero sí es destacable su incidencia en este sector, y es una apreciación realizada en otros conjuntos al aire libre, caso de los petroglifos gallegos. En un trabajo reciente de Vázquez Rozas (1995) se señala que las formas figurativas, especialmente las antropomorfas, tienden a presentarse en paneles inclinados o de tendencia más vertical que otras grafías; hay que recordar que la orientación predominante en los petroglifos gallegos es la cenital, constituyéndose círculos y cazoletas en el tema más reiterado hacia el cenit (Vázquez Rozas, 1995: 71; Villoch Vázquez, 1995: 52).

Las formas naturales o relieves del soporte se usan en la composición. Así los recuadros grabados que realzan cazoletas naturales en el Santo, o la reexcavación de éstas para señalarlas aún más.

Otro modo de utilizar el espacio para organizar una representación según "tempos" es el que muestra la Roca Grande San Bernardino (Fig. 2). Las escenas se dividen en tres, dos de ellas obli- cuas en el espacio general y otra, en la zona inferior, como complemento del mensaje. El panel 2 queda vacío, dejando un espacio notorio que aumenta la sensación espacio/tiempo entre los opuestos 1 y 3 . Posteriormente, este vacío del panel 2 se cubrió con formas alfabéticas que no incluimos en el calco para no distorsionar la imagen original.

La dicotomía que sugiere la posición de los paneles 1 y 3 se ve ratificada por la aparición mayoritaria de individuos masculinos en el panel $1 \mathrm{y}$ femeninos en el 3 (Lám. II). Ambos grupos están

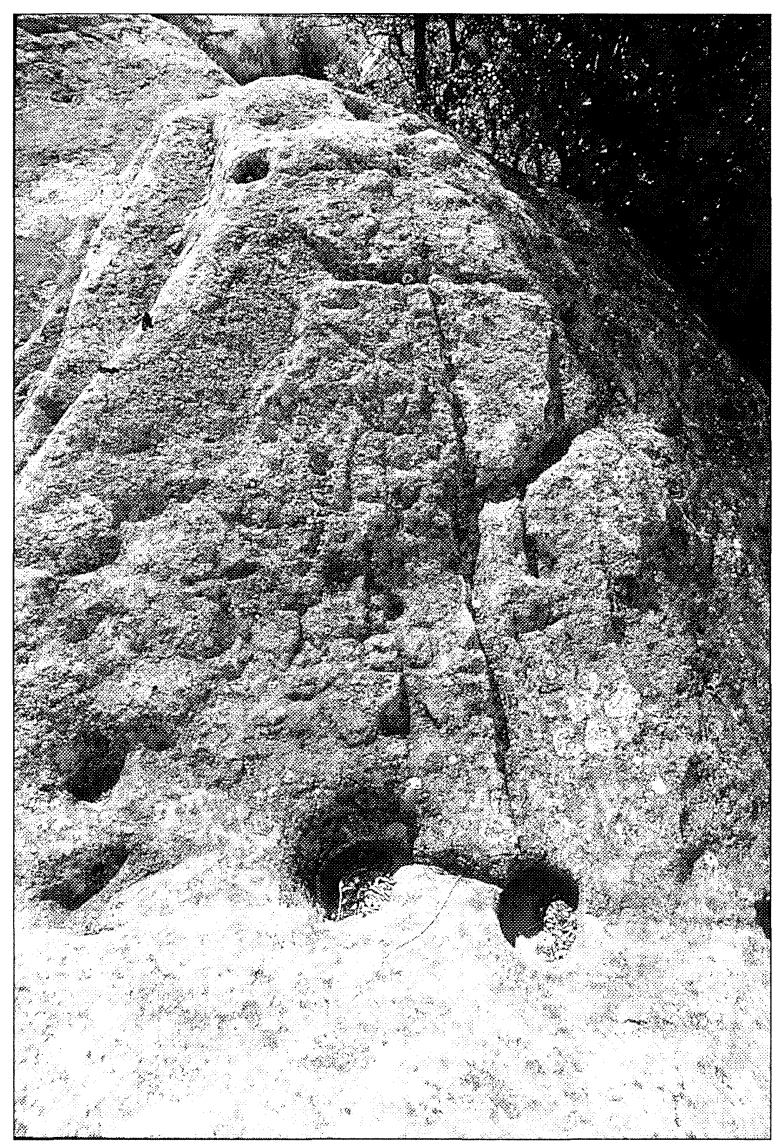

Lám. II. Panel 3 de la Roca Grande de San Bernardino con las figuras femeninas (Foto R. de Balbín).

presididos por una figuración solar (Lám. III) de proporciones considerables que protagoniza igualmente el panel 4 , en el que diversas versiones antropomorfas constituyen otro foco de interés.

Estos recursos aplicados al uso del espacio contribuyen a crear una trama, en la que intervienen contraposiciones de género y lugar, situación más 


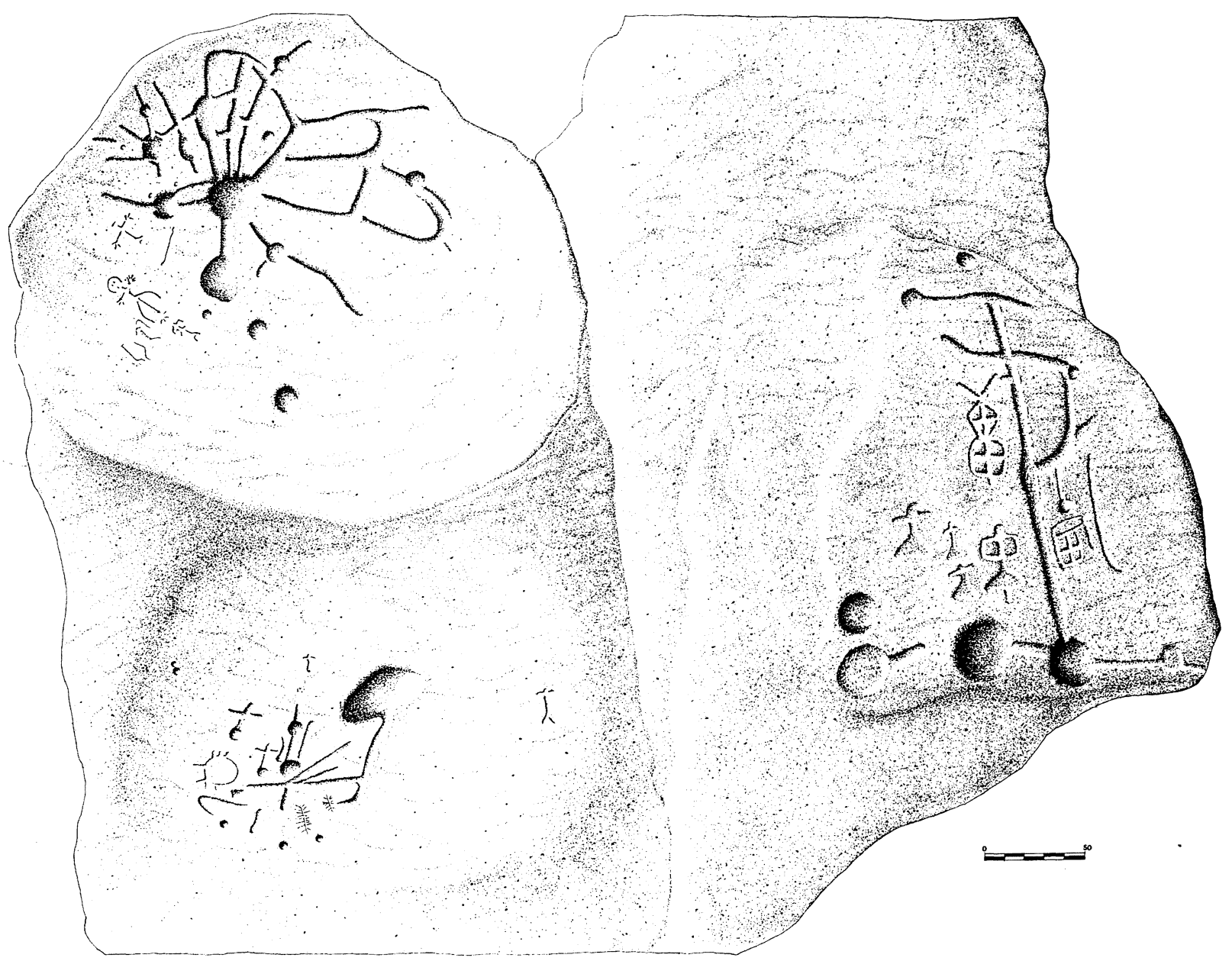

Fig. 2. Calco de los motivos documentados en los paneles 1, 3 y 4 de la Roca Grande de San Bernardino.

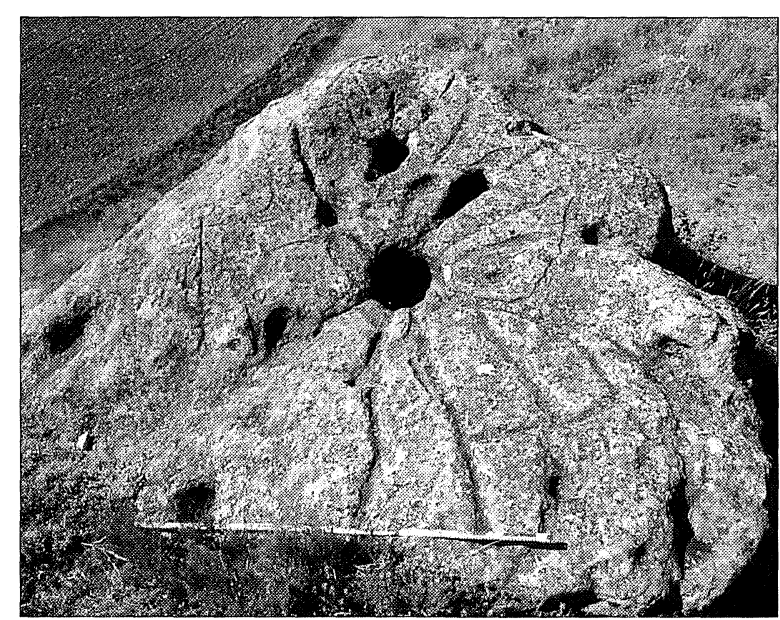

Lám. III. Detalle de la gran cazoleta-sol acompañada de canales-rayos de la Roca Grande de San Bernardino (Foto R. de Balbín). o menos destacada de determinados motivos, y cierto afán de jerarquización, confirmado no sólo por la orientación, sino también por el tamaño de los objetos. Las escenas descritas, los componentes de los grupos y la orientación de aquéllas nos permiten interpretar el conjunto de la Roca de San Bernardino como una danza presidida por el sol, en la que intervienen hombres y mujeres. Si consideramos que la orientación hace que un grupo quede mejor iluminado que otro, según las horas del día, incluso se puede afirmar que hombres y mujeres bailan en horas distintas del día o protagonizan una secuencia continua de danza al sol.

Es más que probable que los rituales allí realizados estuvieran presididos por libaciones u otras ceremonias acompañadas del vertido de líquidos en los gruesos canales y la gran cazoleta central del conjunto descrito, en una versión vitalizadora 


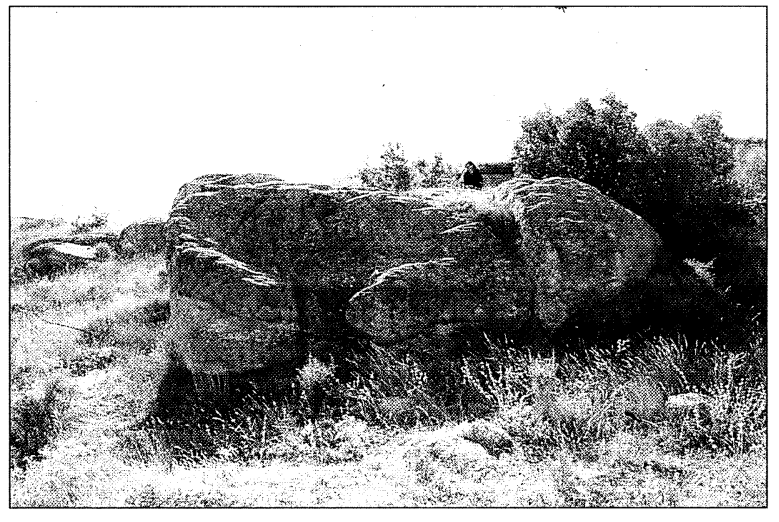

Lám. IV. Situación de la Roca Grande de San Bernardino en las proximidades del afloramiento rocoso de La Hinojosa (Foto R. de Balbín).

de la realidad que contaría con la luz solar y algún líquido acompañante (Lám. IV).

Gráficamente, los grabados de La Hinojosa se resumen en cazoletas y canales, antropomorfos y temas geométricos. Algunos indicios nos permiten suponer que se realizaron cuadrúpedos.

El tema de las cazoletas es mayoritario. Se localizan en todos los paneles descritos en mayor o menor medida, solas o acompañadas de otras grafías.

Su existencia y su adscripción a época prehistórica ha sido objeto de discusión desde muy antiguo. Su situación mayoritaria al aire libre, la posibilidad contrastada de que puedan existir en algunos contextos geológicos de modo natural y la simpleza de su ejecución hacían que una parte de la investigación las desechara como temática prehistórica.

A raíz de nuestros trabajos sobre Arte Megalítico tuvimos ocasión de aportar datos arqueológicos para su contexto en el panorama megalítico (Bueno Ramírez, 1991: 24-25, 1995; Bueno Ramírez y Balbín Behrmann, 1992: 537, 1995).

También es cierto que conocemos cazoletas en contextos más antiguos y más recientes, pero nos parece significativo en el caso que estudiamos su asociación con temas antropomorfos y esteliformes de grafía esquemática. No sólo comparten el territorio de los poblados Calcolítico/Bronce del sector, sino que repiten idéntica orientación a la documentada en otros conjuntos posiblemente contemporáneos, como los grabados gallegos. A ello podemos añadir que representan una figura muy similar a los puntos pintados en el Arte Esquemático y que, como éstos, suelen asociarse a antropomorfos y soles.
Muchas de estas cazoletas aparecen unidas por canales, ejecutando en ocasiones entramados complejos en un sistema compositivo documentado en muchos otros lugares de la Península. Por su proximidad y abundancia señalaremos el conjunto de Tobarrilla, en Murcia (Molina García, 1985).

Algunos de los entramados descritos en La Hinojosa entroncan con la temática solar, como ya hemos señalado, por lo que su relación con ese ambiente de reminiscencias megalíticas es defendible. Recordemos aquí uno de los ortostatos grabados del dolmen de Carapito I con círculos, cazoletas unidas por líneas y soles (Shee Twohig, 1981: fig. 50).

Temas solares grabados al aire libre son comunes en los grabados del Tajo (Gomes, 1983, 1987), en los del Duero (Gómez Barrera, 1992), y desde luego en la Pintura Esquemática (Acosta, 1968). La insistencia del grabador en el tema circular acompañado de rayos, es decir, la excavación profunda de la cazoleta asociada al piqueteado de las líneas, en un juego de técnicas que da volumen a lo representado, es también común. Para no ser exhaustivos recogeremos un elemento similar publicado muy recientemente (Armendáriz, 1996) en Navarra, junto a los sepulcros megalíticos de Artajona.

Grandes paneles con profusa figuración de cazoletas se conocen en otros sitios. Recordaremos aquí las del Canalizo del Rayo (Jordán Montes y Sánchez Gómez, 1988), en Albacete, por su proximidad geográfica y fuerte relación formal. Los grabados se encuentran próximos a dos abrigos con pintura esquemática y a yacimientos del Bronce, aunque también es cierto que el Tolmo de Minateda, ibérico y romano, no queda tampoco muy alejado. Su situación al borde de un farallón, sobre un rico valle, vía de paso tradicional, es igualmente destacada por los autores del estudio. Para ubicarlas cronológica y culturalmente en época prehistórica argumentan la presencia en el interior de una de las covachas próximas, la de la Retuerta, de una gran cazoleta en el suelo utilizado durante la Edad del Bronce. A ello añaden que el poblado del Aribalejo (Bronce II) en Yecla posee en una zona interior del mismo una gran cazoleta muy excavada de $2 \mathrm{~m} . \times 1,5 \mathrm{~m}$. acompañada de otras más pequeñas y de algunos canalillos (Jordán Montes y Sánchez Gómez, 1988: 152).

La última versión, la de las cazoletas profundamente excavadas, está también presente en La Hi-

T. P., 55, n. ${ }^{\circ} 1,1998$ 


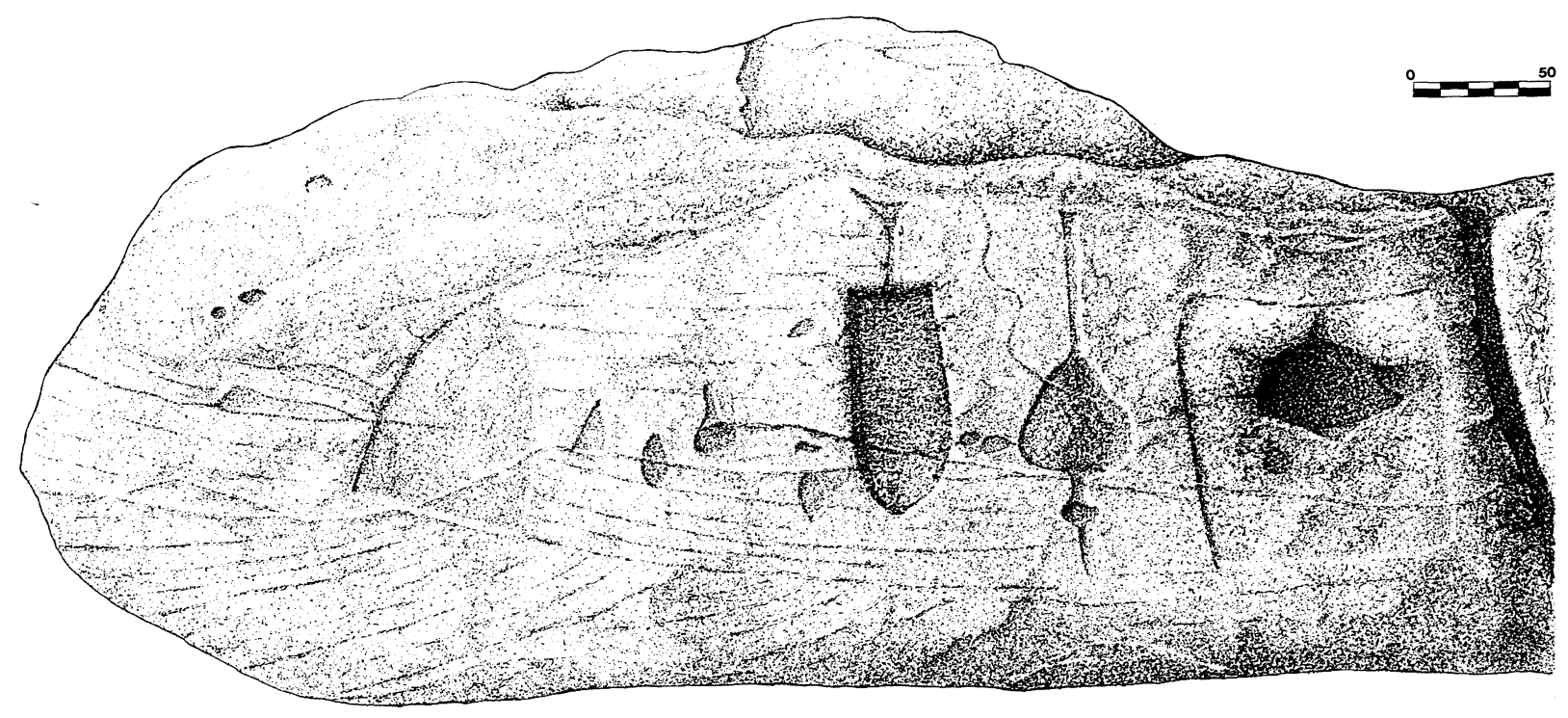

Fig. 3. Calco del panel principal de «El Santo».

nojosa. En ocasiones, estas fuertes excavaciones adoptan formas rectangulares u oblongas como las que hemos descrito en el conjunto del Santo (Fig. 3). La tradición popular las denomina "pilas" y se reconocen en otros lugares de la Península. Ya hemos mencionado el argumento arqueológico que proponen Jordán Montes y Sánchez Gómez (1988) para ubicarlas en la Edad de Bronce. Molina García (1985) trata este aspecto al estudiar el conjunto de Tobarrilla en Murcia y alude a su paralelo con formas semejantes en petroglifos gallegos, que A. de la Peña y Vázquez Varela (1979: 104) interpretan como formas históricas. Éstos no aportan, sin embargo, documentación sobre la forma, medidas o técnica de grabado de las mismas.

Lo cierto es que, aun siendo formas de tendencia rectangular, repiten el sistema que hemos observado en cazoletas y canales (Lám.V). Están relacionadas unas con otras del mismo modo, e incluso en alguna ocasión usan formas naturales y se enmarcan en un recuadro piqueteado como en el panel principal del Santo, de un modo muy semejante al que recogen Jordán Montes y Sánchez Gómez en la covacha de La Retuerta.

Las cazoletas pueden formar parte de temas circulares. Éste es el caso de las que aparecen al interior de los círculos de Las Cabañuelas (Fig. 4). El tema de los círculos con cazoletas al interior o al exterior, con radios o sin ellos, está especialmente bien documentado en el contexto de los petroglifos gallegos (Peña Santos y VázquezVare- la, 1979: 16 y ss.). Es normal que estos círculos estén unidos por líneas como aquí sucede (Lám. VI), lo cual a nuestro entender los asimila muy claramente a la forma antes descrita, cazoletas y canales, pues estructuralmente es una reiteración del tema.

La interpretación de estos temas pasó por una fase en la que fueron considerados propios de un momento avanzado de la Edad del Bronce. Este episodio de la investigación está representado por E. Anati (1968), quien propone establecer una serie de fases consecutivas para el arte gallego al aire libre, con fundamentos poco claros y posteriormente criticadas.

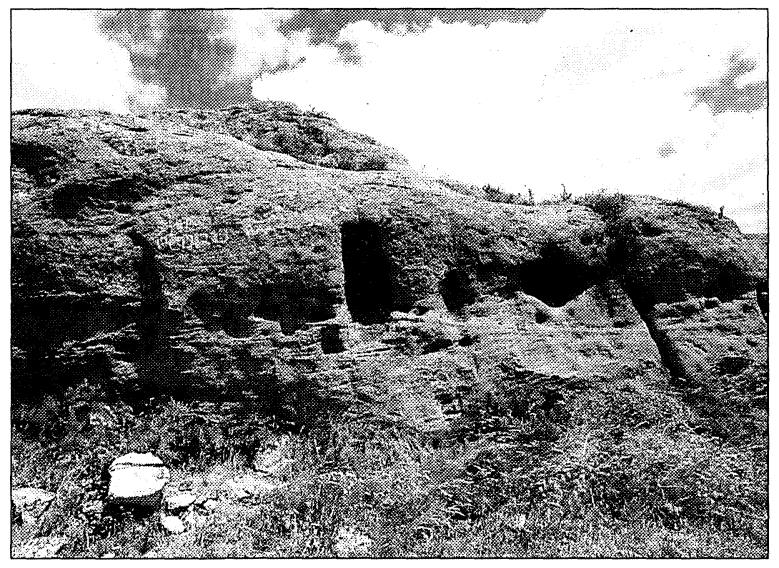

Lám. V. Panel principal de «El Santo» (Foto R. Balbín). 


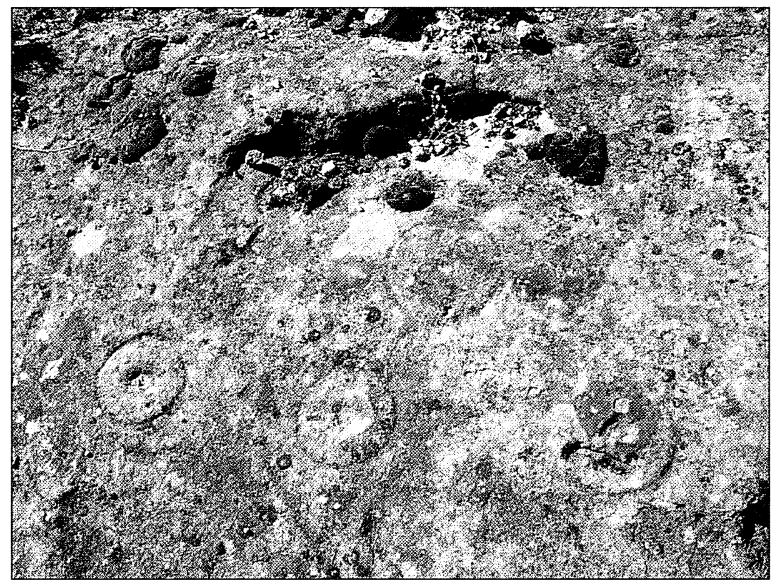

Lám. VI. Panel cenital de Las Cabañuelas (Foto R. de Balbín).

Los análisis más recientes hacen ver la relación espacial del tema circular con las cazoletas. Aparecen sobre los mismos paneles en orientación predominantemente cenital y en territorios megalíticos (Villoch Vázquez, 1995).

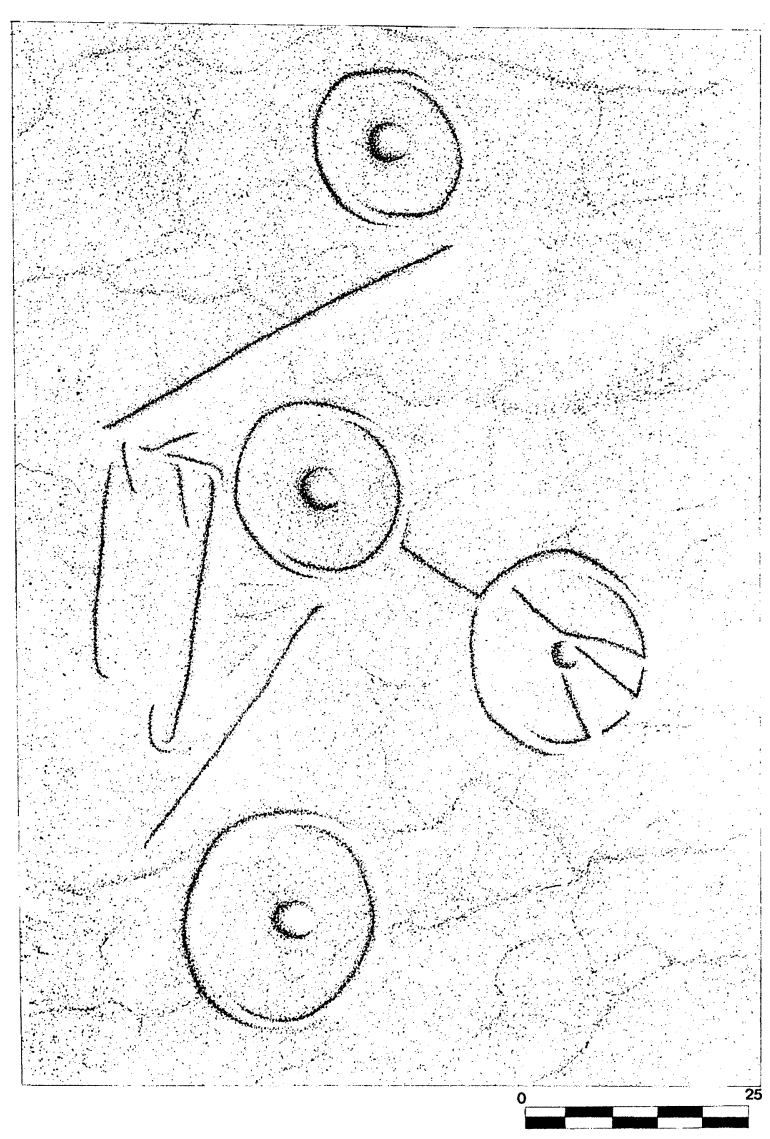

Fig. 4. Calco del panel cenital de Las Cabañuelas.
En otras zonas, como la del Alto Duero, temas circulares como los de La Hinojosa están documentados en abrigo: Barranco de la Mata (Gómez Barrera, 1992: 146-147) y abrigo "f" de Manzanares (Gómez Barrera, 1992: 177). Al aire libre aparecen desde el Suroeste: las Tierras (Belén, 1974) y los Aulagares (Amo, 1974) en Huelva, hasta el Norte.

En el Cantábrico se conocen abundantes cazoletas y canales (Balbín Behrmann et alii, 1983), e incluso temas circulares con cazoletas al interior, unidos por canales como los de Las Cabañuelas. Este es el caso de los grabados de la Cueva del Moro (Díez Castillo y Díaz Casado, 1989), que sus autores relacionan con la ocupación megalítica de la zona.

Temas semejantes se documentan en la pintura esquemática, como ya señaló Gómez Barrera (1992: 364) y poseen un claro nexo gráfico en el mundo megalítico.

Para nosotros la existencia de temas circulares en contextos megalíticos es un hecho demostrado en la Península (Bueno Ramírez y Balbín Behrmann, 1992), tanto en sus versiones más simples, Soto I, Alberite, Granja de Toniñuelo, como en sus versiones más complejas que implican la inclusión de líneas concéntricas, caso de los grabados del ortostato de Monte Eiró.

La reiteración de líneas concéntricas es un recurso gráfico muy extendido en la Europa atlántica desde las primeras manifestaciones de Arte Megalítico (Bradley, 1997). A veces en temas muy elaborados como los que aparecen en el monumento bretón de Gavrinis y a veces en temas circulares, muy similares a los que describimos aquí, caso de los irlandeses de Lougcrew (Shee Twohig, 1981: 207 y ss.) asociados sobre todo a soles y a círculos simples.

Proporcionalmente, cazoletas unidas o no por canales, cazoletas con rayos a modo de soles, círculos con cazoletas al interior con o sin radios, y cazoletas muy excavadas a veces de formas rectangulares u oblongas unidas o no por canales, son los motivos más representados. De hecho, todos los paneles que hemos descrito contienen alguna de sus versiones.

En segundo lugar, desde el punto de vista cuantitativo se encuentran los elementos antropomorfos. Éstos adoptan distintas versiones desde las más simples a las más elaboradas (Tab. 3). Evidentemente, la más simple de todas es la de la esquematización compuesta por dos trazos perpen-

T. P., 55, n. $^{\circ} 1,1998$ 


\begin{tabular}{|l|l|l|l|l|l|l|l|}
\hline & 1 & 2 & 3 & 4 & 5 & 6 & 7 \\
\hline Peñas Mollana & & & & & $*$ & & \\
\hline C. S. Bernardino & $*$ & $*$ & $*$ & $*$ & $*$ & $*$ & \\
\hline Las Solanillas & & & & & & & $*$ \\
\hline Viñas Viejas 1 & & $*$ & & & & & \\
\hline Peña Buitre & $*$ & & & $*$ & & & * \\
\hline Las Cabañuelas & & & & & & & $*$ \\
\hline
\end{tabular}

Tab. 3. Tipos de antropomorfo identificados en los grabados al aire libre de La Hinojosa. 1, Cruciformes. 2, Cruciformes con tope geométrico. 3, Brazos en asa. 4, Esquemáticos. 5, Halteriformes. 6, Ramiformes. 7, Rectangulares.

diculares que denominamos tradicionalmente cruciformes. Éstos aparecen grabados mediante piqueteado de trazo ancho y sección en "U" como en la Roca Grande de San Bernardino.

La discusión acerca de su adscripción prehistórica se establece por la simplicidad del motivo, por su situación al aire libre y por su papel en la simbología religiosa del mundo occidental. Todas estas premisas son igualmente aplicables a su estudio en la Pintura Esquemática (Acosta, 1968: 36-37) donde están documentados y no se ponen en cuestión. El conocimiento de formas semejantes en contextos dolménicos (Bueno Ramírez y Balbín Behrmann, 1992: 511-544, 1996b: 61, 1997: 704) permite afirmar la existencia de esta versión desde épocas antiguas, por lo que no deberían adscribirse mecánicamente a momentos históricos.

Estas formas simples a veces poseen adiciones de carácter geométrico, especialmente círculos o cazoletas y triángulos, tanto en su zona inferior como en su zona superior. A este tipo pertenecen algunas de las figuras del panel 4 de la Roca Ġrande de San Bernardino, y dos de Peña del Buitre.

En ocasiones estas bases geométricas (que aparecen también en la simbología católica como peanas de cruz), si son triangulares se han considerado como faldas, esquema típicamente femenino. Las figuras antropomorfas del panel 3 de la Roca Grande San Bernardino responden a este tipo. Formas similares grabadas están documentadas en el Alto Duero, especialmente en el conjunto del Barranco de la Mata, donde son asimiladas a los triángulares de la Pintura Esquemática (Gómez Barrera, 1992: 136-137).
Siguiendo con los cruciformes de terminación geométrica en la zona superior o inferior, hay que mencionar la gran figura de Peña Buitre, con los brazos cruzados en forma de aspa y cerrados en semicírculo en la parte superior (Fig. 5). Un elemento similar pero menos terminado y de menor tamaño, aparece sobre otra de las superficies decoradas. Nosotros los hemos interpretado como antropomorfos esquemáticos. No poseen referencias concretas en la Pintura Esquemática y la única que conocemos grabada se localiza sobre uno de los túmulos próximos al cromlech de Sejos, en Cantabria (Bueno Ramírez et alii, 1985).

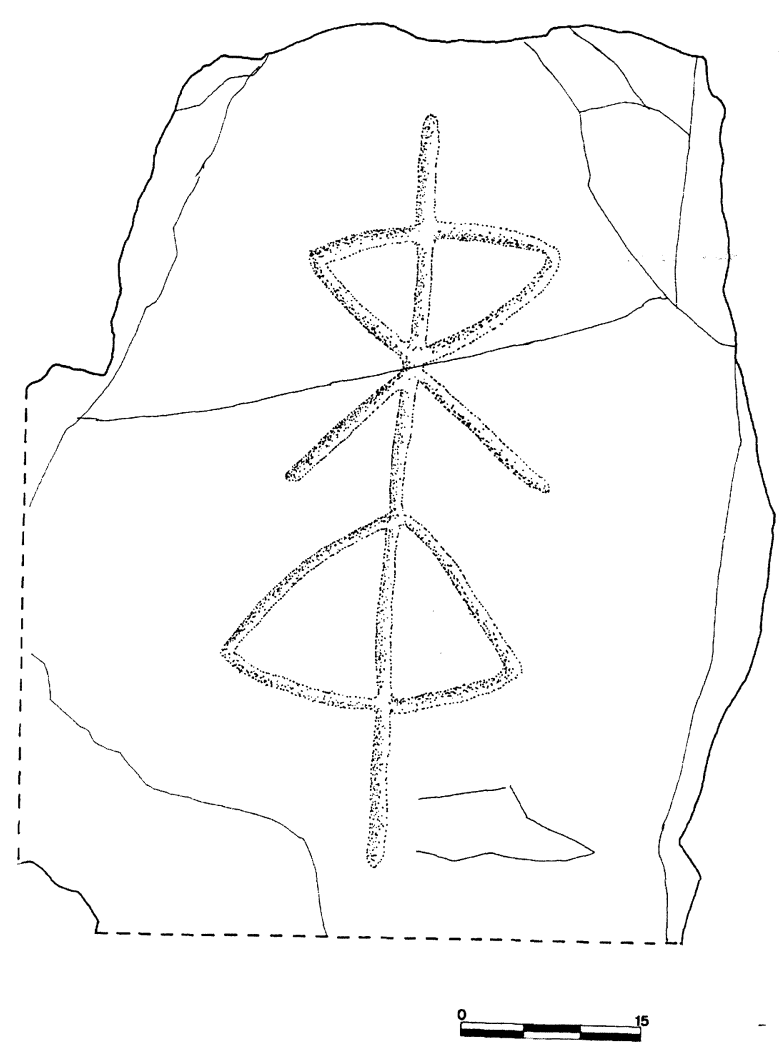

Fig. 5. Calco del antropomorfo cruciforme de mayor tamaño de Peña del Buitre.

También cruciforme pero con rectángulos en la línea transversal, es el ejemplo de Viñas Viejas (Fig. 6). Su forma coincide con algunos de los esquemas que P. Acosta (1968: 29) recoge como antropomorfos de brazos en asa, especialmente los del Callejón del Reboso del Chorrillo, en Ciudad Real. Un grabado similar tenemos de nuevo en el 


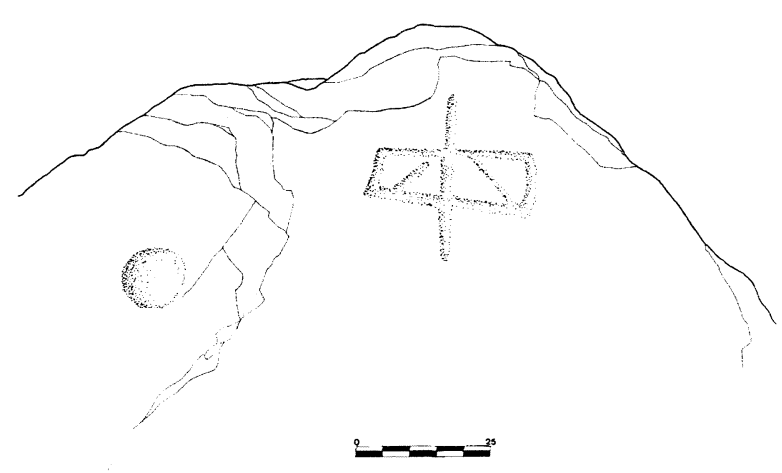

Fig. 6. Antropomorfo de brazos en asa y cazoleta de Viñas Viejas.

Barranco de la Mata (Gómez Barrera, 1992: 137). Otro antropomorfo de brazos en asa es la figura con falda del panel 3 de la Roca de San Bernardino.

Cruciforme en su diseño básico es el clásico antropomorfo esquemático de brazos abiertos y piernas abiertas. Tenemos una representación abundante en la Roca Grande de San Bernardino, panel 4.

Este tipo aparece bien documentado en la Pintura Esquemática de la misma provincia. Así en las Peñas del Castellar (Alonso et alii, 1982: 136), del conjunto de Villar del Humo.Y desde luego es también conocido en el repertorio del Arte Megalítico, tanto pintado, caso de Huidobro (Burgos) (Delibes y Rojo, 1989: 51) como grabado, en el dolmen de la Estrella (Toledo), igualmente al interior de la Península (Bueno Ramírez, 1991: 89; Bueno Ramírez y Balbín Behrmann, 1992: 544). En la Estrella está asociado a cruciformes simples y a cazoletas.

Estas formas las tenemos grabadas en el repertorio del Alto Duero, en los abrigos de la Cañada del Monte, y son interpretadas por Gómez Barrera (1992: 221) como una clara trasposición de tipos de la pintura esquemática prehistórica.

Otro tipo que entronca bastante bien con la Pintura Esquemática y con el repertorio que conocemos en el Arte Megalítico es el ramiforme. Disponemos de ejemplos como los de la Roca de San Bernardino, panel 4, con ramas transversales oblicuas hacia arribá y enmarcados en un rectángulo, como el del Santo.

En la provincia conocemos ramiformes pintados en la Peña de Aldebarán (Piñón, 1987: fig. 1), en un estilo caracterizado por la rigidez compositiva que se relaciona bien con ramiformes graba- dos en megalitos, por ejemplo el del sepulcro de Magacela (Bueno Rodríguez y Balbín Behrmann, 1992: 553).

Estas formas pueden aparecer inscritas en un rectángulo, como decíamos arriba, y poseen referencias en la Pintura Esquemática (Acosta, 1968: 129), además de en el repertorio del Alto Duero, grabados en los abrigos de la Cerrada de la Solana (Gómez Barrera, 1992: 137).

Las grafías hasta aquí analizadas poseen como referencia básica común la cruz, de la cual se parte para representar figuraciones de apariencia antropomorfa. Sólo quedan fuera de este modo básico los halteriformes y los elementos rectangulares.

Los halteriformes simples están compuestos por una barra que tiene a cada uno de sus extremos un elemento circular. Tenemos un ejemplo en la Roca Grande de San Bernardino. Se conocen en la Pintura Esquemática (Acosta, 1968: 83) y en contextos megalíticos como el dolmen de Soto I (Balbín Behrmann y Bueno Ramírez, 1996), por lo que no nos cabe duda sobre su adscripción prehistórica.

También aparecen halteriformes en una versión mixta, como los recogidos por Acosta (1968: 83) en la Covatilla de San Juan, compuestos por triángulos y halteras. Esta forma es bastante asimilable a los ejemplos descritos en las Peñas de Mollana, cuya distinta terminación podría interpretarse como una diferenciación sexual (Fig. 7).

Las grafías rectangulares adoptan diversas versiones. La zonas superior puede ser semicircular,

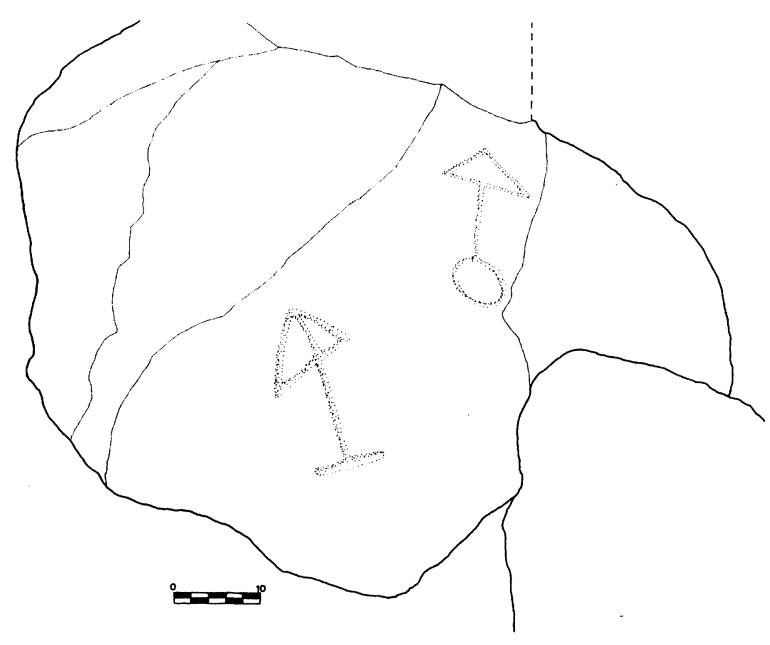

Fig. 7. Halteriformes de Peñas de Mollana. 


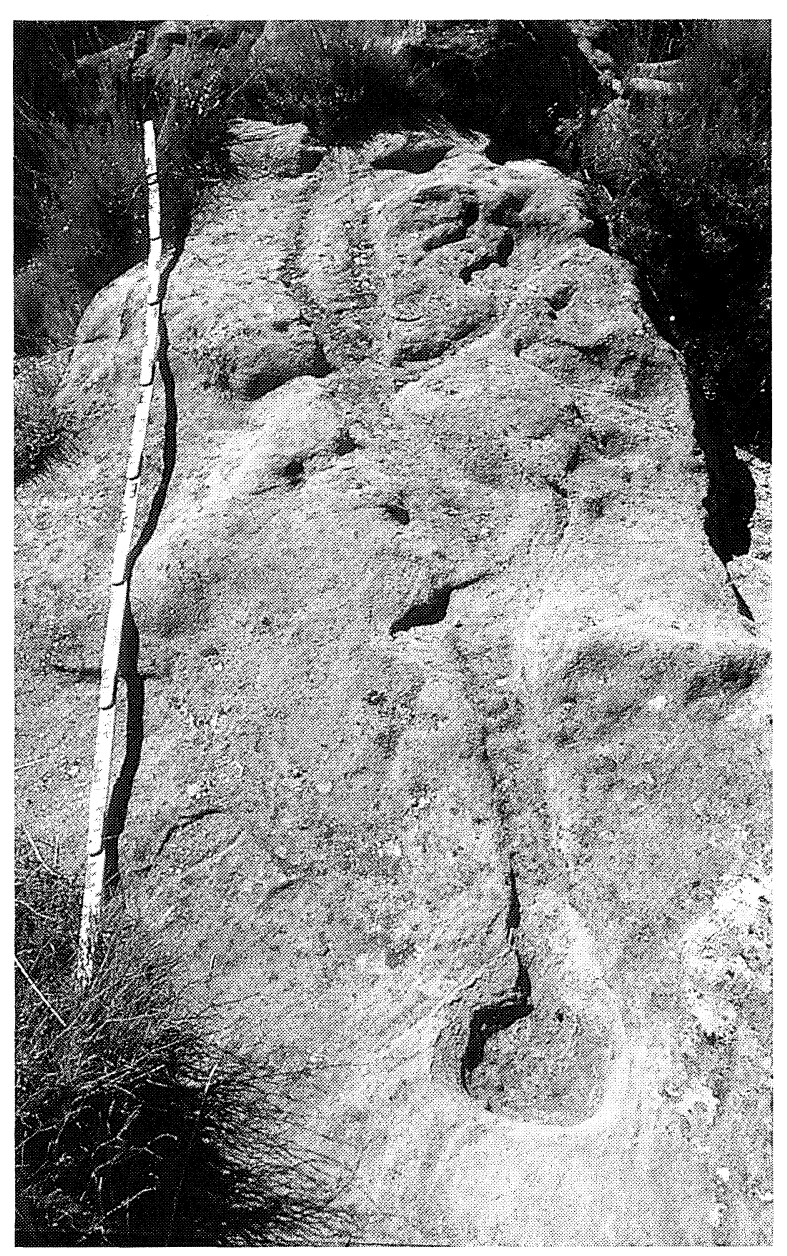

Lám. VII. Panel de Las Solanillas (Foto R. de Balbín).

como en Las Cabañuelas y en Las Solanillas (Lám. VII). En ambos casos, su asociación es manifiesta con elementos circulares, posibles alusiones solares. Estas formas rectangulares con tope semicircular se conocen en pintura, especialmente en la provincia de Badajoz (Acosta, 1968: 87) y constituyen base para algunas piezas antropomorfas de carácter escultórico. La misma estela procedente de la Cruz de San Bernardino responde a este esquema (Fig. 8 y Lám. VIII).

Uno de nosotros (Bueno Ramírez, 1990, 1991, 1992, 1995) ha tratado en más de una ocasión las piezas referidas que se sitúan en Portugal y en el Norte de la Península. Estas piezas no muestran indicación específica de sexo y, en algunas ocasiones, aparecen armadas. La estela de la Cruz de San Bernardino repite un esquema conocido: rectángulo con zona superior semicircular, representación de ojos y del semicírculo de la cara, sin más

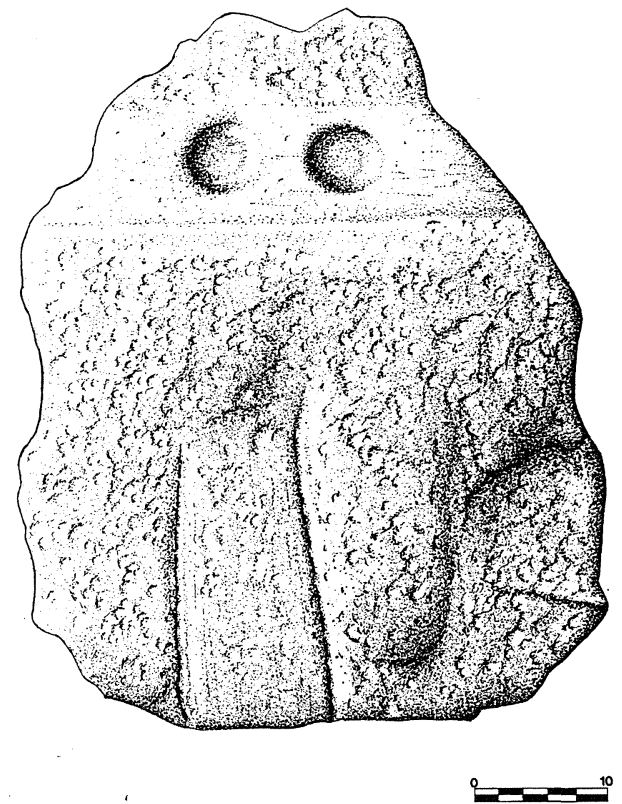

Fig. 8. Calco de la estela de la Cruz de San Bernardino.

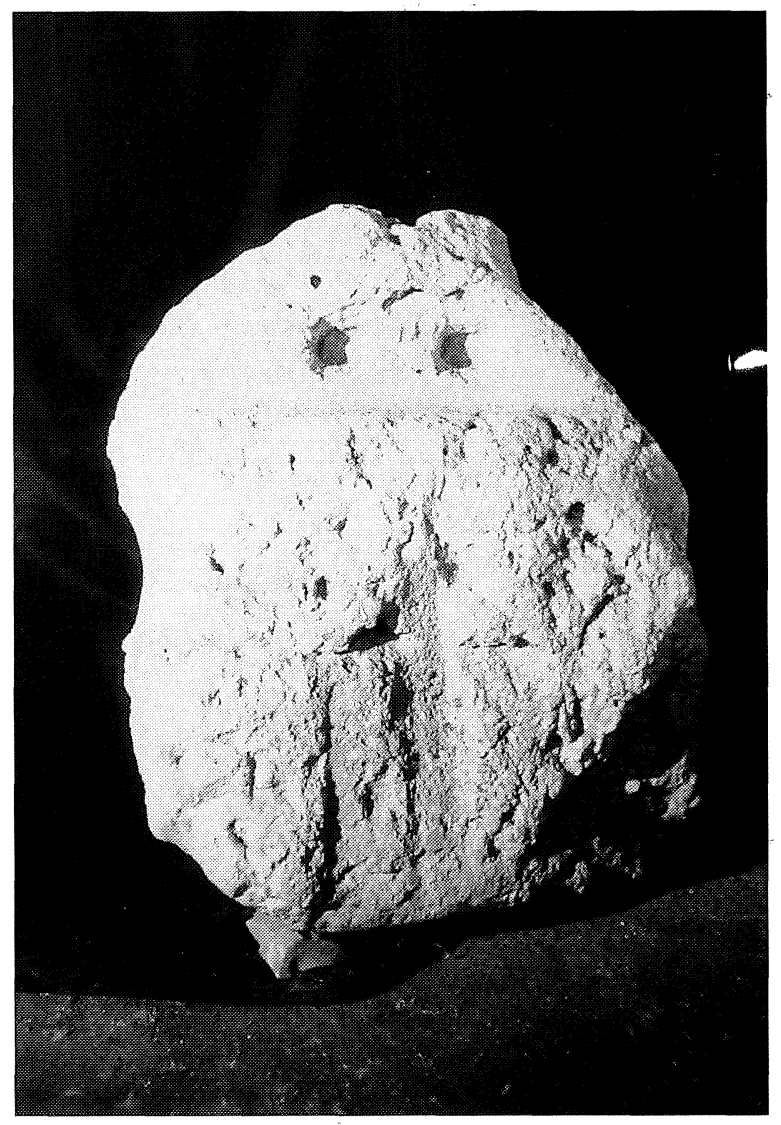

Lám. VIII. Estela de la Cruz de San Bernardino (Foto R. de Balbín). 
detalles anatómicos. Su relación gráfica con piezas como Ntra. Sra. da Esperança es evidente, así como con otros ejemplares: Moncorvo, Sta. Luzía, Peña Tú, Sejos, Tabujo o Garabandal (Bueno Ramírez, 1990: 90 y ss.; 1995: 89 y ss.). La misma existencia de la pieza en cuestión ratifica la identificación de los grabados con versiones antropomorfas.

Al aire libre están documentadas formas semejantes, especialmente al Norte. Nos referimos a los grabados de Ruanales, en Cantabria y Monte Hijedo; entre Burgos y Cantabria. En Ruanales, la figura muestra un puñal a la cintura como la estatua-menhir de Villar del Ala, en Soria (Bueno Ramírez, 1995: 94). El grabado de Ruanales posee otra condición interesante y es que sobre el panel vertical en el que se encuentra, se han grabado cazoletas y canales en orientación cenital y muy próximas se encuentran las pinturas del Cubular (Díaz Casado, 1993: 29-40). Se trata, pues, de un conjunto con antropomorfo, cazoletas, canales y pintura.

Nos parecen asimilables a este grupo las formas rectangulares con cabeza destacada como la descrita en Peña Buitre, que además presenta un objeto triangular a la altura de la cintura, en disposición transversal, idéntica a la de Ruanales o Villar del Ala. Es, por tanto, una estatua armada grabada en la roca (Fig. 9 y Lám. IX).

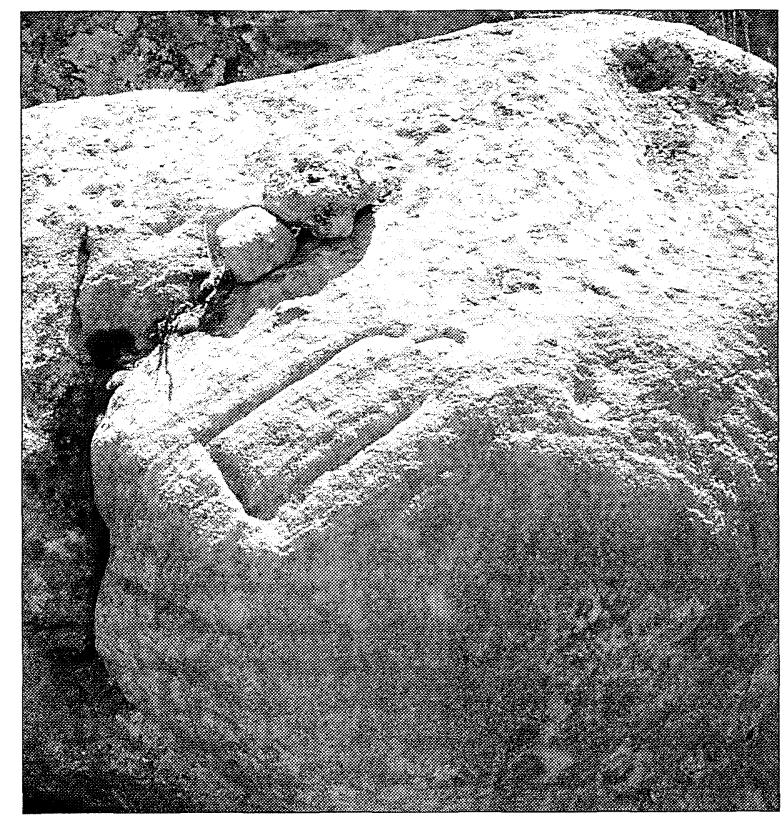

Lám. IX. Situación del antropomorfo armado de Peña Buitre (Foto R. de Balbín).

Otras representaciones son los elementos geométricos de difícil interpretación. Tenemos ejemplos en la Roca Grande de San Bernardino.

El componente geométrico de las grafías prehistóricas es un hecho desde el Arte Paleolítico y, desde luego, los paralelos a estas formas son mu-

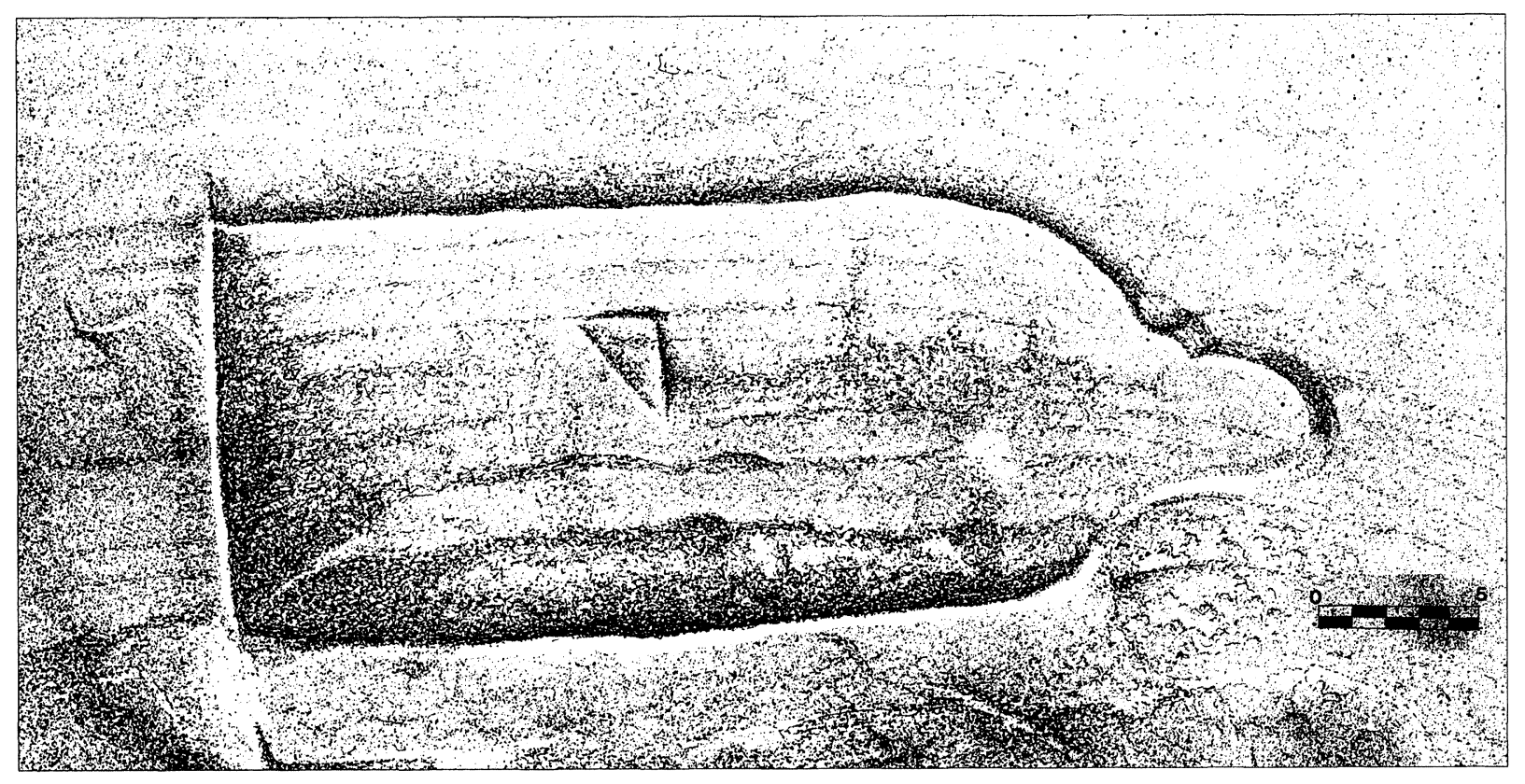

Fig. 9. Calco del antropomorfo armado de Peña Buitre. 
chos, tanto en la Pintura Esquemática como en los grabados al aire libre. Destacaremos su documentación en la Cueva de los Letreros (Almería), junto a gran cantidad de representaciones humanas (Martínez García, 1989).

Un último tipo a comentar es el cuadrúpedo del Ranal, que identificamos como un caballo, aunque no se conserva completo (Fig. 10). La presencia de grabados de cuadrúpedos al aire libre es bien conocida en todos los conjuntos que venimos mencionando: petroglifos gallegos, grabados del Tajo, grabados del Alto Duero.

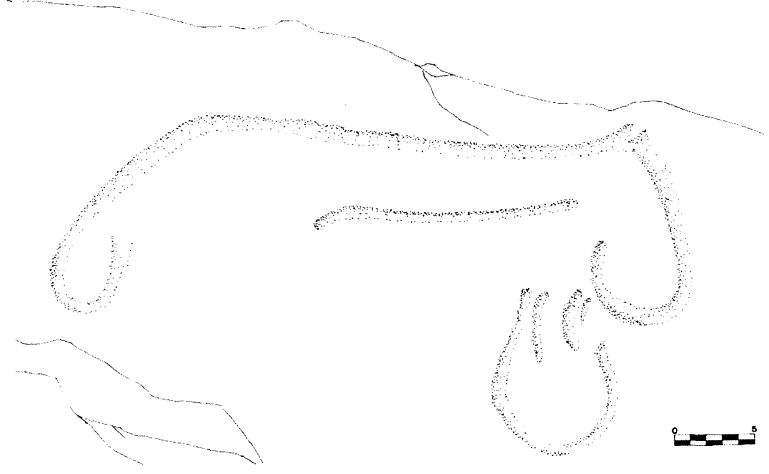

Fig. 10. Calco del cuadrúpedo del Ranal.

En Galicia, aunque predominan los cérvidos, hay caballos grabados. Se caracterizan por su poco naturalismo y por aparecer montados por figuras humanas (Peña Santos y Vázquez Varela, 1979: 60-61). En el grupo del Tajo, hay una figura de caballo con detalles como las orejitas, asimilable al que tenemos en el Ranal y otro menos completo (Batista, 1981: 24-25).

Poseemos otra referencia en el poblado de los Barruecos de Malpartida de Cáceres. En un abrigo del poblado calcolítico se han grabado unos caballos. El conjunto se completa con otros abrigos grabados y pintados (González Cordero y Alvarado, 1985).

Gómez Barrera señala su presencia en los grabados del Alto Duero reparando en la escasez de paralelos en otros conjuntos al aire libre peninsulares. Aparte de los ejemplares montados que no se relacionan con el aquí analizado, el autor señala la presencia de équidos en el Barranco de la Mata, aunque el estilo de éstos no es tan depurado como el del Ranal. Dentro del repertorio por él indicado, se asemeja bastante a uno de los équidos pintados en la Cueva del Torilejo de Valonsadero, Soria (Gómez Barrera, 1992: 359).
Si bien no son muchos los ejemplos, los mencionados del Tajo se datan en el IV milenio a.C. por paralelos con otras manifestaciones, y los que recogemos de Malpartida están en un poblado calcolítico. Los pintados en Soria forman parte de un conjunto pictórico que pertenece a la Pintura Esquemática clásica.

Las grafías descritas no se analizan aisladamente, tienen sentido en cuanto reflejan organizaciones semejantes, en el contexto de la Pintura Esquemática, en contextos megalíticos o en otros grupos de grabados al aire libre.

\section{TERRITORIO GRÁFICO, TERRITORIO ECONÓMICO}

$\mathrm{Al}$ igual que otras manifestaciones de la actividad humana, los grabados al aire libre no ocupan un lugar aleatorio. Su situación y distribución ha sido elegida y pensada por los grupos humanos calcolíticos y de la Edad del Bronce que ocuparon el territorio de La Hinojosa. La fecha de realización de los mismos es imposible de precisar, pero sí creemos posible, tras los argumentos estilísticos y gráficos arriba expuestos, y los topográficos que expondremos a continuación, afirmar que los grabados se realizaron en momentos contemporáneos al desarrollo de los hábitats vecinos.

Los grabados mantienen una situación de visibilidad entre sí y con los poblados adyacentes, que está en relación con la voluntad de sus autores respecto a la visibilidad de sus producciones gráficas. Por tanto, nos reflejan el concepto del espacio de un conjunto social y nos hablan de una "estrategia de visibilización" (Criado Boado, 1993: 45). Los grabados que analizamos aquí constituyen un modo de "escritura", puesto que pretenden comunicar y, por tanto, responden a una forma específica de comunicación concebida como estrategia de apropiación del espacio y, muy probablemente, de identificación del grupo.

Si algo destaca en la ubicación de los grabados de La Hinojosa es su relación con el borde más alto del farallón rocoso que se encuentra sobre el valle. Este farallón posee distintos escalones en altura, en los que se plasman los grabados. De ese modo, se observan claramente varios planos atendiendo a la visibilidad de las insculturas entre sí (Fig. 11).

Uno, compuesto por la relación que se establece entre la Roca Grande de San Bernardino y El 


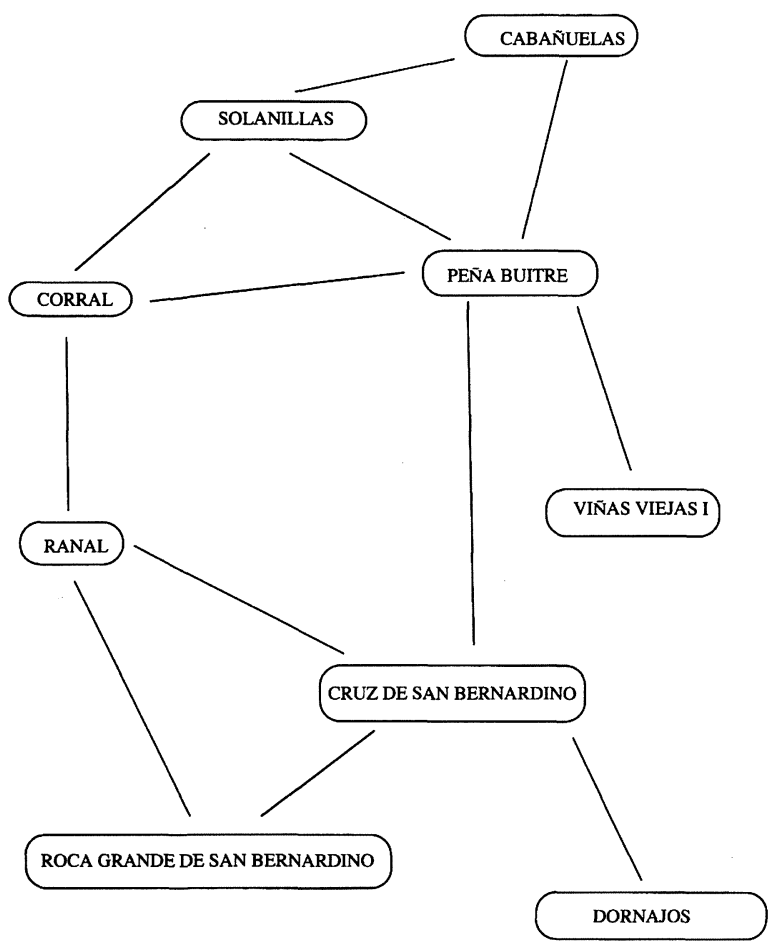

Fig. 11. Representación gráfica de los diversos planos de relación visual de los grabados al aire libre de La Hinojosa.

Ranal; otro, por el Corral y Las Solanillas; uno, más alto, compuesto por la Cruz de San Bernardino, Peña Buitre, Viñas Viejas y Las Cabañuelas. Desde la Cruz de San Bernardino y desde Peña Buitre se controlan todos los demás. Los Dornajos, poblado calcolítico y de inicios de la Edad del Bronce se relaciona visualmente con la Roca Grande de San Bernardino y la Cruz de San Bernardino.

De este modo, en el sector Noroeste de la Hinojosa, la relación visual entre los grabados en sus diversos planos altimétricos, y los poblados con restos de la época, forma una cadena claramante establecida que une todas las localizaciones descritas. En conjunto cubren los puntos más notorios del farallón rocoso sobre el valle que grosso modo podríamos resumir en dos escalones: el señalizado por la Roca Grande de San Bernardino, Ranal, Corral y Solanillas y el marcado por Dornajos, Cruz de San Bernardino, Peña Buitre, Cabañuelas y Viñas Viejas. En este escalón entraría también la situación de la población actual de La Hinojosa, si se confirma su ocupación en esos momentos. El conjunto de todas las loca- lizaciones forma a su vez una figura más o menos circular que deja al interior una parte importante de la zona más alta sobre el valle, en la que están bien documentados restos diversos-hachas pulimentadas y yacimientos off site que demuestran su gran ocupación durante la época de la que hablamos.

Al Suroeste de La Hinojosa sólo tenemos documentado Peñas de Mollana y El Santo, ambos en una altura de 900 m., muy similar a la del escalón representado por Roca Grande de San Bernardino, El Ranal... etc. Las dos localizaciones tienen conexión visual entre sí y a su vez con el poblamiento antiguo de La Hinojosa que representaría el escalón superior.

Las localizaciones de grabados sobre el farallón rocoso coinciden nítidamente con la situación de los poblados y restos que pueden catalogarse en el Calcolítico e inicios de la Edad del Bronce. En la secuencia de mapas adjunta (Fig. 12) se observa cómo la situación de estos restos prácticamente se superpone a la de los grabados.

La inclusión de las insculturas en un contexto cultural calcolítico concuerda con los datos que hemos manejado desde el punto de vista gráfico y estilístico para situar su realización. A ello hemos de añadir que en la cerámica campaniforme con la que se conecta el estilo Dornajos, las figuraciones de animales, seres humanos y soles están bien documentadas (Blasco et alii, 1994).

Algunos de los grabados poseen una relación aún más marcada con estos núcleos habitacionales: se encuentran dentro de ellos. Este es el caso del Ranal y de San Bernardino. Por tanto, la conexión espacio gráfico/espacio habitacional no es en La Hinojosa sólo de proximidad, sino de clara imbricación.

La teoría tradicional de los "santuarios" aplicada tanto al Arte Paleolítico como al Arte Postpaleolítico, implicaba de alguna manera la separación entre vivienda y lugar con arte, pues se entiende que el espacio habitacional hace referencia a lo cotidiano, mientras que el espacio ritual es un espacio diferenciado, en algunos casos oculto (esto, sobre todo, por lo que se refiere al Arte $\mathrm{Pa}$ leolítico).

Los datos nos indican que existen muchos yacimientos Paleolíticos con Arte rupestre utilizados al mismo tiempo como vivienda (Zilhao et alii, 1996), o cuya situación al aire libre dista mucho de la necesidad de ocultamiento de los "santuarios" (Balbín et alii, 1994, 1996). 

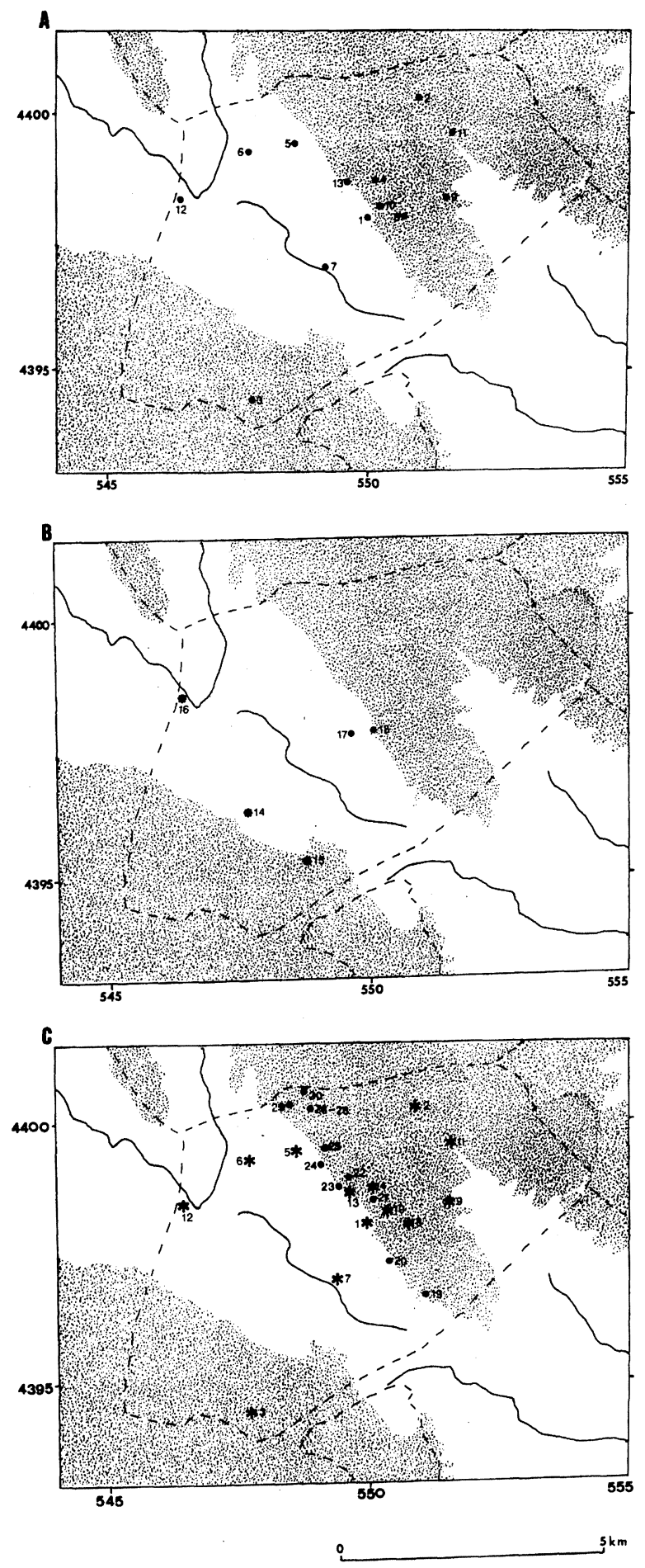

Fig. 12. A. Situación de poblados calcolíticos y hallazgos aislados de probable cronología calcolítica en término de La Hinojosa. Yacimientos off site: 1. Las Acequias, 2. Cañaro, 3. Fuente del Colmenar, 4. Huerto Molla, 5. El Ranal, 6. El Setar; probablemente calcolíticos: 7. Agua de los Co- tos, 8. Cardona, 9. La Olivilla; hachas pulimentadas: 2. Cañaro, 10. Cercado de Arsenio, 11. Retuerta, 12. Venta de la Espada; yacimientos con cerámica campaniforme tipo Dornajos: 13. Los Dornajos. B. Situación de yacimientos de la Edad de Bronce (*) en término de La Hinojosa: 14. Cerro de la Talayuela, 15. Cabeza Gorda, 16. Sima del Alamillo. Yacimientos de la Edad del Hierro (•): 17. El Navazo/El Cuadro, 18. El Palomar/La Atalaya. C. Yacimientos calcolíticos $\left(^{*}\right)$ y estaciones con grabados al aire libre $(\bullet)$ en término de La Hinojosa. 1. Las Acequias, 2. Cañaro, 3. Fuentes del Colmenar, 4. Huerto Molla, 5. El Ranal, 6. El Setar, 7. Agua de los Cotos, 8. Cardona, 9. La Olivilla, 10. Cercado de Arsenio, 11. Retuerta, 12. Venta de la Espada, 13. Los Dornajos, 19. Peñas de Mollana, 20. El Santo, 21. la Butrera, 22. San Bernardino, 23. La Roca Grande de San Bernardino, 24. El Corral, 25. Las Solanillas, 26-28, Viñas Viejas, 29. Peña Buitre, 30. Cabañuelas.

Algunos indicios ya publicados hacían pensar lo mismo para el Arte Postpaleolítico, aunque la conexión habitat/grafía esquemática había quedado en cierto modo solapada por la idea generalizada de la interpretación de estas grafías como una cuestión religiosa desarrollada en "santuarios", en lugares distantes a los núcleos de habitación.

Nos parece difícil mantener la denominación de "santuarios" aplicada genéricamente a cualquier manifestación pintada o grabada. Más bien se dibuja una variedad de funcionalidades de la expresión gráfica que poco a poco se podrá delimitar. Puede hablarse de territorios funerarios, especialmente señalizados con menhires decorados, dólmenes pintados y grabados $\mathrm{y}$, muy posiblemente, elementos construidos en materiales perecederos que no han llegado hasta nosotros. También podemos plantear la existencia de marcadores económicos, territoriales, de expresiones gráficas relacionadas con los lugares de habitación y utilizadas como indicación de control de un determinado territorio. Así interpretamos los grabados de La Hinojosa.

La asociación grabados al aire libre/poblados no es única en el caso que nos ocupa pero hasta la fecha no se había reparado en ella como reflejo de una estrategia concreta.

Este es el caso del "santuario" exterior de Escoural, en Portugal, así denominado por su investigador M. Varela Gomes (1983b). Sobre la cueva de Escoural, que contiene manifestaciones de estilo paleolítico, se localiza un habitat calcolítico. 
En el suelo de éste, algunas rocas aparecen grabadas con motivos circulares y otro tipo de figuraciones de interpretación varia. Dichas rocas a veces aparecen cubiertas por derrumbes del poblado calcolítico lo que para el autor es indicio de que se grabaron con anterioridad. Sea como fuere, lo que está claro es que algunas rocas eran visibles en época del poblado calcolítico, formaban parte de su espacio vital y, por tanto, poseían un significado para los habitantes del lugar. El espacio de la representación y el de habitación están aquí claramente fundidos, como en los ejemplos que hemos comentado de La Hinojosa.

Otro ejemplo semejante es el poblado de los Barruecos, en la provincia de Cáceres (González Cordero y Alvarado Gonzalo, 1985). Se trata de un hábitat calcolítico en cuyo espacio se sitúan además de restos de cabañas, abrigos con pinturas y abrigos con grabados esquemáticos, entre los que destacan cazoletas, figuraciones circulares y representaciones de équidos.

Ambos ejemplos -que no son los únicos conocidos- nos remiten a contextos calcolíticos pero existen también ejemplos del mis-mo esquema asociativo gráfico/espacio habi-tacional, en épocas más recientes. El caso más espectacular es el yacimiento deYecla deYeltes en Salamanca (Martín Valls, 1983). Se trata de un poblado amurallado cuya vida comienza en la Segunda Edad del Hierro. Parte del lienzo de sus murallas y de las rocas sobre las que se asientan, muestra grabados con temas circulares o con temas animales -ciervos y caballos montados-, en un estilo que recuerda bastante al grupo gallego. Los trabajos en el poblado han continuado, y en la actualidad la muralla está completamente restaurada, habiéndose localizado en ella muchos ejemplos de los conocidos, que reiteran la realidad de unos grabados contemplados y realizados en el momento de uso del yacimiento, quizá como símbolo del poder o posesiones de sus habitantes.

En definitiva, los grabados al aire libre suelen disponer de un contexto espacial que permite ubicarlos culturalmente. En el caso de los que aquí hemos analizado, este contexto es especialmente claro, pues nos indica la convivencia del espacio representativo con el habitacional, proponiendo dudas razonables respecto a la interpretación exclusiva de este tipo de yacimientos gráficos como "santuarios".

Muy probablemente estos grabados engloben una multiplicidad de significados al igual que la mayor parte de los mensajes que nosotros recibimos. Pretender explicaciones sencillas y unidireccionales supone reducir los sistemas de relación de los grupos que analizamos, minimizar su comprensión del entorno, y en suma disfrazar la complejidad de su organización.

La sociedad reflejada en estas manifestaciones gráficas utiliza estrategias de apropiación del espacio para señalar su dominio sobre un territorio, constituyendo la situación de los grabados un marcador expreso de la situación del grupo, de su control sobre el valle adjunto. Que los grabados posean este papel no nos parece incompatible con otros significados sociales, rituales, mitológicos, etc., que ayudan a la cohesión del grupo, a su identificación como tal.

Las grafías prehistóricas han debido constituir un medio de expresión grupal que actúa como detentador de la tradición, como identificador del grupo, definidor de territorios, además, por supuesto de los significados que deben poseer en relación con la economía, la ritualidad, las tradiciones, etc. Se trata, en suma, de un lenguaje, pese a que nosotros no seamos capaces de desentrañarlo y hayamos dejado de lado en muchos casos, especialmente en el de los grabados al aire libre, su análisis e interpretación.

\section{BIBLIOGRAFÍA}

Acosta, P. (1968): La pintura rupestre esquemática en España. Salamanca.

- (1983): "Estado actual de la prehistoria andaluza: Neolítico y Calcolítico”. Habis, 14: 195-205.

Almagro Basch, M. (1946): "El arte español desde el Neolítico a la Edad del Bronce (3.000-1.000) antes de Jesucristo". Ars Hispaniae, 1: 91-107.

- (1966): "El ídolo de Chillarón y la tipología de los ídolos del Bronce I Hispano". Trabajos de Prehistoria, XXV.

Alonso, A. (1984): "Los conjuntos rupestres de Marmalo y Castellón de los Machos, Villar del Humo. Cuenca". Empuries, 45-46: 8-29.

- (1985): "Villar del Humo, un núcleo rupestre olvidado". Revista de Arqueología, 45: 12-23.

Alonso, A.; Merglejo, M.; Medina, O. y Carrión, A.M. (1982): "Las pinturas de la Peña del Castellar (Villar del Humo,Cuenca)". Zephyrus, XXXIV-XXXV: 133140.

Aмо, M. del (1974): "Los grabados rupestres de Los Aulagares (Zalamea la Real, Huelva)". Miscelánea Ampuritana. XXV Aniversario de los Cursos de Ampurias (1947-1971), I: 69-86.

T. P., 55, n. ${ }^{\circ} 1,1998$ 
ARMENDÁRIZ, A. (1996): "Una nueva cazoleta rupestre en el grupo de Las Negueas, en la Navarra media." Cuadernos de Arqueología Navarra, 4: 79-84.

Atrian JoRdán, P. (1980): "Los grabados rupestres del Barranco Cardoso. Almohaja (Teruel)". Revista Teruel, 64.

Balbín Behrmann, R. de (1989): "Arte megalítico y esquemático en el Norte de la Península Ibérica". Cien años después de Sautuola. Santander: 11-91.

Balbín Behrmann, R. de; Alcolea, J. y Santonja, M. (1994): "Siega Verde y el arte rupestre Paleolítico al aire libre". 6 Coloquio Hispano-ruso de Historia. Fundación Cultural Banesto. Madrid: 5-19.

- (1996): Arte rupestre Paleolítico al aire libre de la Cuenca del Duero: Siega Verde y Foz Coa. Fundación Rei Afonso Henriques. Zamora.

Balbín Behrmann, R. de y Bueno Ramírez, P. (1981): "Avance sobre el yacimiento de Arte Esquemático de la Tinaja, Ruidera. Albacete". Altamira Symposium. Madrid: 551-565.

- (1994): Arte postpaleolítico en Castilla-La Mancha. La Edad del Bronce en Castilla-la Mancha.Toledo: 87-109.

- (1996): "Soto,un ejemplo de Arte Megalítico al Suroeste de la Península Ibérica". En A. Moure (ed): «El Hombre fósil» 80 años después. Santander: 467-505.

Balbín Behrmann, R. de; González Morales, M.; Serna González, M. y González SAInZ, C. (1983): "Informe sobre el conjunto de grabados rupestres al aire libre de la Braña de los Pastores Cabrojo. Santander". Zephyrus, XXXVI: 94-104.

Batista, A.M. (1981): A rocha F-155 e a origem da arte do Vale do Tejo. G.E.A.P. Porto.

Blasco, M.C.; Recuero, V.; Jiménez, C. y Gutiérrez, C. (1994): "Manifestaciones simbólicas". En C. Blasco (ed.): El horizonte Campaniforme de la región de Madrid en en centenario de Ciempozuelos. U.A.M. Madrid: 249-263.

Becares, J.; Martínez Navarrete, M. I. y Pérez de la SiERRA, J.V. (1985): "Representación antropomorfa de la Sima 'Cabeza de la Fuente' (Boniches. Cuen-

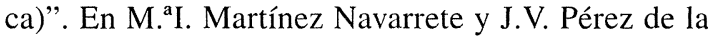
Sierra: La Sima 'Cabeza de la Fuente' Boniches. Arqueología Conquense, 6. Cuenca: 123-143.

Belén Deamos, M. (1974): "El petroglifo de 'Las Tierras' (Villanueva de los Castillejos, Huelva)". Trabajos de Prehistoria, 31: 337-348.

BRADLEY, R. (1997): Rock Art and the Prehistory of Europe. Signing the land. Routledge. London.

Bradley, R.; Criado, F. y FÁbregas, R. (1994a): "Los petroglifos como forma de apropiación del espacio: algunos ejemplos gallegos". Trabajos de Prehistoria, 51 (2): $159-168$.

- (1994b): "Rock art research as landscape archaeology: a pilot study in Galicia, north-west Spain". World Archaeology, 25 (3): 374-389.
Bradley, R. y FÁbregas, R. (1996): "Petroglifos gallegos y Arte Esquemático". Complutum. Extra II: 103-110.

BREUIL, H. (1935): Les peintures rupestres Schémathiques de la Péninsule Ibérique. Lagny. París.

Bueno Ramírez, P. (1983): "El ídolo de Parra de las Vegas”. Noticiario Arqueológico Hispánico, 16: $197-$ 199.

- (1990): "Statues-menhirs et stèles anthropomorphes de la Péninsule Ibérique". L'Anthropologie, 94 (1): 85-110.

- (1992): "Les plaques décorées aléntejaines: approche de leur étude et analyse". L'Anthropologie, 96 (2-3): 573-604.

- (1995): "Megalitos, estatuas y estelas en España". En Statue-stele e massi incisi nell'Europa dell'etá del Rame. Notizie Archeologiche Bergomensi, 3: 77-129.

Bueno Ramírez, P. y Balbín Behrmann, R. de (1992): “Art mégalithique dans la Péninsule Ibérique. Une vue d'ensemble". L'Anthropologie, 96 (2-3): 499-572.

- (1995): "La graphie du serpent dans la culture mégalithique péninsulaire.Représentations de plein air et représentations dolméniques". L'Anthropologie, 99 (23): 357-381.

- (1996a): "La decoración del dolmen de Alberite". En F. Ramos y F. Giles (eds.): El dolmen de Alberite (Villamartín). Aportación a las formas económicas y sociales de las comunidades neolíticas en el noreste de Cádiz. Cádiz: 285-312.

- (1996b): "El papel del elemento antropomorfo en el Arte Megalítico ibérico". Révue Archéologie de l'Ouest. 8: 41-64.

- (1997): "Ambiente funerario en la sociedad megalítica ibérica: Arte megalítico peninsular". En A. Rodriguez Casal (ed.): $O$ Neolítico atlántico e as orixes do megalitismo. Actas do Coloquio Internacional (Santiago de Compostela, 1996): 693-718. Santiago de Compostela.

Bueno, P.; Piñón, F. y Prados, L. (1985): "Excavaciones en el Collado de Sejos (Valle de Polaciones, Santader)". Noticiario Arqueológico Hispánico, 22: 27. 53.

Bullón, T. y DíAz-ANDReu, M. (1992): "La relación entre formas de relieve y asentamientos de la Edad del Bronce en el área de Cervera del Llano (Cuenca)". Cuaternario y Geomorfología, 6: 99-101.

Criado BoAdo, F. (1993): "Visibilidad e interpretación del registro arqueológico". Trabajos de Prehistoria, 50: 39-56.

Delibes de Castro, G. y Rojo Guerra, M. (1989): "Pintura esquemática en el sepulcro de corredor burgalés de «El Moreco» Huidobro". Arqueología, 20: 49-55.

DíAZ-Andreu, M. (1994): La Edad del Bronce en la provincia de Cuenca. Cuenca.

Díaz Castillo, A. y Díaz Casado, Y. (1989): "Los grabados de la Cueva del Moro (San Mamés. Polaciones. Cantabria)". Zephyrus, XLI-XLII: 493-496. 
Díaz CASAdo, Y. (1993): El arte rupestre esquemático en Cantabria. Universidad de Cantabria.

Gomes, M. V. (1983a): "Arte esquemático do Vale do Tejo". Zephyrus , XXXVI: 277-285.

- (1983b): "O santuario exterior do Escoural.Sector N.E. (Montemor-o-Novo, Evora)". Zephyrus, XXXVI: 277-307.

- (1987): "Arte rupestre do vale do Tejo". Arqueología no Vale do Tejo. I.P.P.A.R.: 27-43.

Gómez BARrera, J.A. (1992): Grabados rupestres postpaleolíticos del Alto Duero. Soria.

González Cordero, A. y Alvarado Gonzalo, M. (1985): "Pinturas esquemáticas y grabados rupestres de Los Barruecos (Malpartida de Cáceres)". Actas de las II Jornadas de Metodología y Didáctica de la Historia. Univ.Extremadura: 154-168.

Hernández Pacheco, E. (1921): "Exposición de arte prehistórico español Arte español". Revista de la Sociedad de Amigos del Arte, V (7): 315-339.

Hernández Pérez, M.; Ferrer Marset, P. y Catalá FeRRER, E. (1986): "Arte rupestre en el Estret de les Aïgues (Bellús, Xátiva.Valencia)".Lucentum, 5: 5-22.

- (1988): Arte rupestre en Alicante. Banco de Alicante. Alicante.

JoRdÁn Montes, J.F.; SÁNCHEZ GómEZ, J.L. (1988): "Las insculturas de el Canalizo de El Rayo (Minateda). Albacete". I Congreso de Historia de Castilla-La Mancha. Talavera: 147-163.

Martín Valls, R. (1983): "Las insculturas del castro salmantino deYecla deYeltes y sus relaciones con los petroglifos gallegos". Zephyrus, XXXVI: 217-231.

Martínez Fronce, F.M. (1991): "La cañada Real de los Chorros en su trayecto conquense". Revista de Cuen$c a, 38: 45-65$.

Martínez García, J. (1989): “Análisis de un sistema de parentesco en las pinturas rupestres de la Cueva de los Letreros (Velez Blanco.Almería)". Ars Praehistórica, VII/VIII: 183-193.

Martínez Navarrete, M. ${ }^{a}$ I. y Pérez de la Sierra, J.V (1985): La sima del Cerro "Cabeza de la Fuente". Boniches, Cuenca. Serie Arqueología Conquense, VI. Patronato Arqueológico Provincial. Excma. Diputación Provincial y Excmo. Ayuntamiento de Cuenca. Cuenca: 9-143.

Martínez Perelló, M.I. y Díaz Andreu, M. (1992): "El abrigo pintado de la Hoz de Vicente (Minglanilla. Cuenca)". Espacio, Tiempo y Forma. Serie I, Prehistoria y Arqueología, V: 177-206.
MaYA, J.L. (1977): “La Peña del Guisaero, estación con grabados esquemáticos en la provincia de Albacete". XIV C.N.A.: 515-524. Zaragoza.

Molina García, J. (1985): "Campo de petroglifos en Tobarrilla.Yecla (Murcia)". Noticiario Arqueológico Hispánico, 25: 135-161.

Peña Santos, A. de la y Rey García, M. (1993): "El espacio de la representación. El arte rupestre galaico desde una perspectiva territorial". Pontevedra, 10: 11-50.

Piñón Varela, F. (1987): "Arte Esquemático en Cuenca:las pinturas rupestres de la peña de Aldebarán (Valdemoro de la Sierra)". Bajo Aragón Prehistoria, VII-VIII: 147-157.

Sevillano San José, C. (1991): Grabados rupestres de la comarca de las Hurdes. Salamanca.

Shee Twohig, E. (1981): The megalithic art of western Europe. Clarendon Press. Oxford.

VÁzQUEZ RozAs, R. (1995): "Los petroglifos gallegos: selección de su emplazamiento y selección de las rocas grabadas". Actas del XXII C.N.A. (Vigo, 1993), I: 6976، Vigo.

VICENT GARCíA, J.M. (1994): "La digitalización del archivo de arte rupestre post-paleolítico del Departamento de Prehistoria del Centro de Estudios Históricos (CSIC), Madrid". Boletín Informativo del Instituto Andaluz del Patrimonio Histórico, II, 7: 41-43.

Vicent García, J.M.; Montero Ruiz, I. y Rodríguez AlCALDE, A.L. (1997): "Digital image processing and prehistoric art. The digitalizing of the Rock Art Archives of the Departamento de Prehistoria (Centro de Estudios Históricos, CSIC)". Tracce on Line Rock Art Bulletin, 8 (http://www.geocities.com/Athens/3857/ levant.html).

Vicent García, J.M.; Montero Ruiz, I.; Rodríguez AlCalde, A.L.; Martínez Navarrete, M. ${ }^{\text {II }}$ y Chapa BRUNET, T. (1996): “Aplicación de la imagen multiespectral al estudio y conservación del arte rupestre postpaleolítico". Trabajos de Prehistoria, 53 (2): 1935.

Villoch Vázquez, V. (1995): “Monumentos y petroglifos: la construcción del espacio en las sociedades constructoras de túmulos del Noroeste peninsular". Trabajos de Prehistoria, 52 (1): 39-55.

Zilhão, J.; Aubry, T.; Carvalho, A.F.; Zanbujo, G. y AlMEIDA, F. (1995): “O sitio arqueológico paleolítico do Salto do Boi (Cardina, Santa Comba, Vila Nova de Foz Coa). Dossier Coa. S.P.A.E. Porto: 167-194. 